\title{
Is stock liquidity transferred and upgraded in acquisitions? Evidence from liquidity synergies in US freeze-outs
}

\author{
Konstantinos Konstantaras $^{1} \cdot$ Vasilios Sogiakas $^{2}$ (D)
}

Published online: 12 May 2018

(C) The Author(s) 2018

\begin{abstract}
This paper investigates the value successful bidders generate from acquiring less liquid targets. This synergy is traced with both theoretical and empirical evidence from the squeeze-out stage of going private transactions, when bidders hold sizeable toeholds in target shares. By transferring their superior liquidity, acquirers can add value to the valuation of their toeholds in fully acquired target assets. We use a sample of US delisted targets from globally listed acquirers over 25 years, and, in line with our theoretical analysis, a nonlinear relation is evidenced between the expected added value from liquidity transfer and illiquidity differences. The adjustment of target market prices for the attached option to participate in the bid in a new stochastic volatility framework reveals that the bulk of deal-generated wealth depends on the offered option. Although the market penalizes the mean acquirer with negative abnormal returns, those with higher liquidity differences from their targets are suffering less because of their greater potential of liquidity transfer synergy. The analysis of the probability that the offered option gets in the money reveals that liquidity transfer acts as a catalyst for successfully concluding the deal and underlies underbidding.
\end{abstract}

Keywords Liquidity $\cdot$ Going private $\cdot$ Squeeze out $\cdot$ Freeze out

\section{Introduction}

The puzzle of why acquirers of unlisted and subsidiary targets earn higher abnormal returns than those of public firms is attracting academic interest. The main reason is that none of the existing theoretical suppositions, namely synergy, target financial liquidity, target valuation

Vasilios Sogiakas

vasilios.Sogiakas@Glasgow.ac.uk

Konstantinos Konstantaras

kkonstantaras@glos.ac.uk; konstantinos.konstantaras@yahoo.com

1 University of Gloucestershire, Gloucester, UK

2 University of Glasgow, Glasgow, UK 
uncertainty, and target bid resistance, are able to adequately account for this phenomenon (Jaffe et al. 2015). This paper suggests an explanation based on stock liquidity differences between the acquirer and its target. The important role for both bidder and target stock trading liquidity in mergers and acquisitions (Massa and Xu 2013; Officer 2007) is extended to acquisitions of less liquid targets. We suggest that bidders with superior stock trading liquidity can transfer their liquidity characteristics to their fully acquired targets through going private transactions. In a stock market environment where liquidity is valued, rendering acquired assets more liquid can lower the required investor returns, increase their market price (Amihud and Mendelson 1986) and generate value to bidders. We empirically estimate and attest the existence of these liquidity synergies in going private deals where the transfer of liquidity is monetized, upon successful deal consummation, on the valuation of bidder toehold in target shares. Although overall bidder abnormal returns are not positive, in line with the existing empirical findings (Bates et al. (2006), henceforth BLL), in tandem with the market's higher expectation of liquidity transfer synergies, they become less negative. Valuing the target shareholder's option to participate in the bid with a methodologically improved stochastic volatility valuation, we find supporting evidence of liquidity transfer's contribution to underbidding. Last but not least, liquidity transfer synergy reduces the probability that the bid is overbid, in line with Amihud et al. (2004) theoretical model. To the best of our knowledge, we are the first to formally estimate with our new methodology these liquidity synergies, based on a simple theoretical framework, offering a plausible solution to the puzzle.

These synergies can arise on the valuation of their toehold in target's stock, whenever acquirers with a more liquid stock acquire less liquid, listed, or unlisted targets. In particular, the value stemming from this synergy is rendered measurable by taking a closer look at the economics of squeeze-outs, ${ }^{1}$ the last stage of going private deals. At this point, bidders, with a sizable toehold in the target, offer cash or stock to the remaining minority shareholders with the publicly announced intention to collect in excess of a $90 \%$ stake and subsequently remove it from the exchange. It is worth stressing that at this point there is no need to pay a control premium, facilitating the isolation of its target toehold liquidity's impact on the acquirer market value. Because at the squeeze-out stage bidders hold sizeable toeholds, to the extent that there is a scarcity of target shares, the illiquidity of the target stock and its margin of liquidity difference from the bidder become magnified. The value from liquidity transfer is reflected by the disappearance, following the delisting, of the market's double discounting of a bidder's toehold valuation with a target's illiquidity, on top of the bidder's own stock liquidity discount. This double liquidity discount stems from the disparity of the secondary market liquidity profiles ${ }^{2}$ between the two stocks, reflecting the differences in their individual (Fang et al. 2009) and market trading characteristics (Sarr and Lybek 2002). The termination, following the squeeze-out, of the target's separate market trading removes its own liquidity discount and registers a commensurate increase on the valuation of the bidder's toehold.

To what extent are the hypothesized liquidity-related synergies incorporated in market prices? The analytical measuring of liquidity synergies exposes that bidders taking advantage of these synergies increase their share of deal-generated wealth in more illiquid target freeze-

\footnotetext{
${ }^{1}$ Other terms given for the last stage of going private deals and used interchangeably herein are "squeezeout," "going private merger," "parent-subsidiary merger," "minority buyout," "take out," or "cash-out merger" (Subramanian 2007). The reader is referred to this paper for an in-depth analysis of the legal aspects and insightful discussion. The terms squeeze-out and freeze-out are used herein interchangeably.

${ }^{2}$ For instance, although a wholly owned subsidiary of an NYSE listed parent firm witnesses a severe liquidity markdown if sold privately (Officer 2007), its theoretical value as an integral element of the parent's market capitalization is discounted with the relatively thinner parent company-wide liquidity discount.
} 
outs. Ideally, we would like to compare bidder wealth in the numerous acquisitions of private companies from listed bidders where the liquidity difference margin is more pronounced. However, we can only account for the relative improvement in target stock liquidity for listed targets. Hence, the impact on bidder announcement abnormal returns is estimated and tested on the full sample of 162 US listed firms gone private from their global, albeit mostly US-listed, parents during the 25 years from 1990 to 2014.

In this respect, several econometric challenges need to be circumvented. The first is the prevailing squeeze-out target illiquidity, depicting trading gaps lasting for several days. This is addressed with the trade-to-trade returns adjustment (Maynes and Rumsey 1993). Employing this adjustment in measuring bidder Cumulative Abnormal Returns (CAR) and allowing for the appreciation in their toehold in target shares (Bates et al. 2006; Malatesta 1983) pinpoints that acquirers with liquidity transferring synergies outstrip targets' share. Our results contrast the existing findings for mergers and acquisitions (Andrade et al. 2001) and squeeze-outs in particular (Bates et al. 2006; Croci and Petmezas 2010). It is shown that a lower proportional share of the economic rents accrues to the target's minority shareholders in the overwhelming majority of the US freeze-outs. Bidders capture a bigger part for more illiquid squeeze-out targets.

The next econometric hurdle imposed is isolating the target's theoretical equity value from the market price, which includes the implied option to receive cash or bidder stock. As discussed in Bhagat et al. (1987), the degree to which the offered option is "in the money," i.e. the margin by which the offering price exceeds the target's underlying equity, indicates the market's assessment of intra firm synergies and their relatedness with the target's equity. The existing empirical literature follows their suggested estimation method to calculate the option value in a Black-Scholes, non-stochastic, volatility framework. To account for the time-varying volatility prevalent in the examined deals, a new stochastic option valuation framework is developed herein on the basis of Heston and Nandi's (2000) model. In stock exchange offers, market prices are adjusted for the attached exchange options following Bjerksund and Stensland (1993). Nonparametric tests indicate a significant difference between the estimated option-adjusted and unadjusted returns, registering more than $77.5 \%$ of the average CAR in our sample due to the options granted from the bidder. A second methodological improvement in the analysis is introduced with the estimation of the probability that the granted option is "in the money" as a function of the offered price and the expiration term (Madan et al. 2008). On this basis we find strong evidence that liquidity transfer synergies increase the probability that this option gets "out of the money." This finding shows that the more bidders stand to benefit from liquidity transfer synergies, the less they propose to the underlying. Bidders can aggressively capitalize on liquidity transfer synergy without a commensurate increase in the premium offered to a target's minority shareholders because it can escape the "Fair Value" adjudication imposed by Delaware courts. ${ }^{3}$

The remainder of the paper includes a brief literature overview, which includes the liquidity transfer analysis, in Sect. 2, followed by a description of the empirical methods, including the implied option estimation, in Sect. 3. Section 4 describes our data. Section 5 presents and discusses the results. Section 6 summarizes and concludes the paper.

\footnotetext{
3 US courts, in the case of merger squeeze-outs, can determine fair value for the target's stock, unlike tenderoffer squeeze-outs. In the former, the fair valuation process ignores the target's recent market price, whereas in the latter, market prices play the most influential role (Subramanian 2007). Hence, the illiquidity discount may only play a role in fair market valuations during tender-offers as opposed to mergers, which explicitly rule it out (Hamermesh and Wachter 2009).
} 


\section{Literature review and theoretical formulation}

\subsection{Liquidity transfer analysis}

Acquirers perform better in acquisitions of unlisted or subsidiary targets (Faccio et al. 2006). Jaffe et al.'s (2015) research examines the competing theories which can explain why less liquid, unlisted targets generate higher acquirer returns. Their work empirically dismisses Fuller et al.'s (2002) and Officer's (2007) financial constraints, Cooney et al.'s (2009) underdiversification and risk-aversion and Baron's (1983) target management resistance theories as explanations. However, although Amihud and Mendelson (1986) suggest that more liquid securities are more valuable, Jaffe et al. (2015) do not include stock liquidity, as opposed to financial liquidity, in their analysis.

Going private deals constitute a subset of acquisitions in which trading illiquidity plays a theoretically acknowledged role. The literature emphasizes, besides avoidance of listing costs and subdued benefits from retaining a listing (Mehran and Peristiani 2010), illiquidity as the underlying driver. The probability of going private increases, according to the theoretical models of Holmstrom and Tirole (1993) and Boot et al. (2006), for illiquid firms lacking investor attention. The higher the liquidity, the more easily arbitrageurs can gather large hold-out stakes before the deal announcement and bargain for an amplified premium (Jindra and Walking 2004). Hence, the premium paid in going private deals critically depends on the target's stock liquidity and is cheaper for less liquid targets (Gomes 2001; Cornelli and Li 2002).

The way we estimate the liquidity synergy accruing to the acquirers of less liquid targets is via accounting for the toehold appreciation taking place in gone private targets, due to differences in stock liquidity. At the squeeze-out stage, the last stage of a going private transaction, bidders already in a position of significant toeholds in target stock offer compensation to minority shareholders, with the intention to remove it from the exchange. To the degree that stocks are not perfectly liquid, higher toeholds can feed into additional target stock illiquidity, further alleviating incoming bidding contestants and increasing the probability of bidding success. In this paper, liquidity transfer from a bidder on the valuation of its toehold in less liquid target stock is identified as a toehold synergy, on top of the bid premium and the increased probability of a successful deal outcome (Shleifer and Vishny 1986; Maug 2006). The mechanics of this transfer are described in the following paragraphs.

The valuation of toeholds in illiquid target stock before the squeeze-out deal's consummation, although hard to value correctly (Mehran and Peristiani 2010), reflects the target's illiquidity discount. Following a successful going private deal, toeholds of gone private targets are valued by investors with a unique liquidity discount imposed on the theoretical value of bidder assets. Hence, the double discounting reduces to a much inferior single one for acquirers with more liquid stock than their targets. In effect, successful squeeze-out bidders enjoy analogous benefits to the resolutions of negative stub values (Cochrane 2004), albeit in the opposite direction: instead of resolving the subsidiary's overvaluation via a spin off, they remove their subsidiary's undervaluation due to illiquidity by squeezing it out.

To account for liquidity transfer, we analyze, from the maximization of bidder shareholder valuation perspective, the pro forma synergies before the public announcement of a freezeout merger or tender offer. The upper limit of an economically sound offer, allowing for the absence of a control premium, consists of the target's fair value plus synergies. Assuming the target has $N^{T}$ outstanding shares, it is shown in the "Appendix" that the Law of One Price decomposes the parent's market capitalization before the offering takes place $V_{P R E}^{B / U}$ to the 
value $T V^{\text {Pre }}$ of its toehold $\alpha \in(0,1)$ in the target and the stub value of the rest of its assets $V^{S A}$ :

$$
V_{P R E}^{B / U}=T V^{P r e}+V^{S A}=a\left(1-d^{P}\right)\left(1-d^{T}\right) P_{T h}^{\operatorname{Pr} e} N^{T}+\left(1-d^{P}\right) V_{B P I}^{S A}
$$

where $d^{P}$ and $d^{T}$ represent the market liquidity discounts from their theoretical values of parent and target stocks and $V_{B P I}^{S A}$ is the theoretical stub value, consisting of the value of bidder assets other than the toehold, before liquidity discounting. Until the final deal consummation and the eventual target delisting, the valuation of the toehold experiences a double liquidity discount, as an individual stock from its theoretical value and as part of the parent's assets. The reason for the double discounting lies in the concept of downward sloping stock demand curves (Loderer and Jacobs 1995; Shleifer 1986; Wurgler and Zhuravskaya 2002). The toehold's double liquidity discount reflects the alternative stock demand and supply curves between target and bidder stock. There exists theoretical and empirical support for the existence of double liquidity discounts in, e.g., closed-end funds vis-à-vis the discount of the fund versus the illiquidity of its stock holdings (Cherkes et al. 2009).

Taking the target private entails a successful tender offer or statutory merger at a price of $P^{T O}$ for its remaining $(1-\alpha)$ shares, paying a premium of $P^{P r e m}$ on the target's theoretical price $P_{T h}^{\mathrm{Pr} e}$ :

$$
P^{T O}=P_{T h}^{\operatorname{Pr} e}+P^{\operatorname{Pr} e m}
$$

After being delisted, the full target value, which includes the pre-bid toehold and the squeezed-out shareholding, integrates with the acquirer's market capitalization. Netting other synergies out and assuming the same parent liquidity discount, its stub value remains unchanged. However, two reappraising effects price the toehold: first, the final acquisition premium paid and, second, the acquirer's post-squeeze-out liquidity discount. Taking into consideration the expected liquidity discount of the parent $E\left[d^{P^{\prime}}\right]$ following a successful deal consummation, the toehold registers a revaluation amounting to the difference between its value before and after the deal ${ }^{4}$ :

$$
\begin{aligned}
& T V^{\text {Post }}-T V^{\operatorname{Pr} e} \\
& \quad=a N^{T}\left\{P_{T h}^{\operatorname{Pr} e}\left(d^{P}-E\left[d^{P^{\prime}}\right]\right)+P_{T h}^{\operatorname{Pr} e} d^{T}+P^{\operatorname{Pr} e m}\left(1-d^{P^{\prime}}\right)-P_{T h}^{\operatorname{Pr} e} d^{P} d^{T}\right\}
\end{aligned}
$$

In this expression four sources of added value can be identified, inside the brackets. The first term, representing the parent's long-term liquidity evolution, is positive for an improvement resulting from a thinner discount. The second term represents the margin of value stemming from the acquirer's liquidity transferred onto the target's stock, which is greater for more illiquid targets. The third term is the premium driven reappraisal and the fourth a secondorder term in the two stock liquidity discounts. The second term quantifies the positive role of liquidity transfer's effect on the toehold's reappraisal over and above the effect of the premium. It can directly contribute to a net gain in the parent's market capitalization, to the degree the premium paid leaves room for a positive reappraisal.

The net value added $N V A^{A}$ to the acquirer break-up valuation, following a successful freeze-out, is estimated in the theoretical appendix as:

${ }^{4}$ Detailed calculations can be found in a theoretical appendix posted on the authors' personal website. 
Fig. 1 Liquidity transferring's theoretical worth per dollar of toehold market value over liquidity difference and parent illiquidity. $\Delta d^{T P}=d^{T}-d^{P}$. $\Delta d^{T P}$ : difference in target's versus bidder's stock illiquidity discount, $d^{P}$ : parent's stock illiquidity discount, LiqTransf: theoretical liquidity transferring's worth per dollar of toehold market value

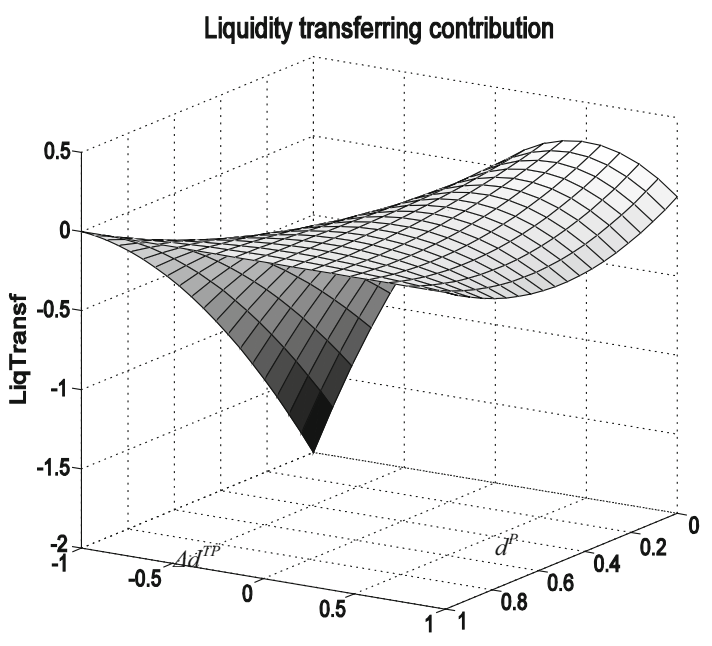

$$
N V A^{A}=\left\{\begin{array}{l}
\Delta d^{P}\left(V_{B P I}^{S A}+N^{T} P_{T h}^{\operatorname{Pr} e}\right) \\
+\Delta d^{T P} N^{T} \alpha P_{T h}^{\operatorname{Pr} e}\left(1-d^{P}\right) \\
-N^{T} P_{T h}^{\operatorname{Pr} e}\left[\left(\alpha-d^{P}\right)-\alpha(1-d)-\alpha\left(1-d^{P}\right)^{2}\right] \\
+N^{T} P^{\operatorname{Pr} e m}\left(\Delta d^{P}-d^{P}+\alpha\right) \\
-c_{T}
\end{array}\right.
$$

In this expression, $\Delta d^{T P}=d^{T}-d^{P}$ is the initial liquidity difference between the parent and the subsidiary stock, $\Delta d^{P}=d^{P}-d^{P^{\prime}}$ is the parent stock's expected long-run illiquidity improvement following the squeeze-out, and $c_{T}$ represents the transaction's legal, investment banking, and operational expenses. Among the alternative sources of net value addition and subtraction to the acquirer, the second term represents liquidity transfer LiqTransf, which can be written as a function of the target's market price $P_{T g}^{\operatorname{Pr} e}$ before the deal announcement as follows:

$$
\text { LiqTransf }=\Delta d^{T P} N^{T} \alpha P_{T h}^{\operatorname{Pr} e}\left(1-d^{P}\right)=\Delta d^{T P} N^{T} \alpha P_{T g}^{\operatorname{Pr} e}\left(1-d^{T}\right)\left(1-d^{P}\right)
$$

Considering that $\Delta d^{T P}=d^{T}-d^{P}$, expression (5) can be written as a nonlinear function of liquidity discounts and differences as follows:

$$
\text { LiqTransf }=N^{T} \alpha P_{T g}^{\operatorname{Pr} e}\left[\Delta d^{T P}\left(1-d^{P}\right)^{2}-\left(\Delta d^{T P}\right)^{2}\left(1-d^{P}\right)\right]
$$

Figure 1 exhibits this nonlinear relation between the hypothetical LiqTransf and a parent's illiquidity $d^{P}$ and the liquidity differences between the two stocks $\Delta d^{T P}$. The vertical axis measures the standardized, by toehold value $N^{T} \alpha P_{T g}^{\mathrm{Pr} e}$, percentage contribution of liquidity transfer's value LiqTransf. The maximum possible liquidity transferring contribution of $25 \%$ is attained at zero parent illiquidity and a positive $50 \%$ illiquidity difference. The influence of $\Delta d^{T P}$ on liquidity transfer's added value is not monotonic. Although a positive $\Delta d^{T P}$ is a prerequisite for a positive contribution of liquidity transfer, its overall impact depends on the interplay with the parent's illiquidity discount $d^{P}$. 
The acquirer stock illiquidity $d^{P}$, according to our formulation for liquidity transfer, has an overall negative impact on the net value added ${ }^{5}$ when squeezing out illiquid targets. Intuitively more liquid, lower $d^{P}$, parents dispose of a larger margin of liquidity difference to transfer to their targets after the deal consummation, delivering superior added value. This leads to the following hypothesis:

Hypothesis 1 The more liquid the parent stock before the deal announcement, the higher the expected added value derived from transferring liquidity onto the gone private toehold.

With respect to the parent stock's long-run liquidity improvement $\Delta d^{P}$, existing empirical evidence on US mergers and tender offers supports a measurable effect. Lee and Chung (2013) indicate it is more profound in mergers rather than tender offers, with targets exhibiting a superior long-run liquidity upgrading to their bidders. In our theoretical analysis, acquirers' long-run illiquidity improvement $\Delta \mathrm{d}^{\mathrm{P}}$ can be a significant factor, as a multiplier of the full theoretical acquirer value in expression (4). Hence, to the degree that there exists an anticipated long run liquidity improvement, it is expected to play a role in deal economics.

\subsection{Liquidity transfer in abnormal returns}

If liquidity transfer is an important economic factor, to the extent the market believes it can add value to the bidder, the latter's abnormal returns on deal announcement can be related to its anticipated effect. Its relative expected magnitude on deal announcement day $t=0$ is empirically estimated using the expectation of expression (5), which, after dropping the expectation operator, is standardized for deal size by dividing it by the premium paid:

$$
\frac{\text { LiqTransf }}{\operatorname{Pr} \text { emium }}=\frac{\Delta d^{T P} N^{T} \alpha P_{T g}^{\operatorname{Pr} e}\left(1-d^{T}\right)\left(1-d^{P}\right)}{N^{T}(1-\alpha) P^{T O}}=\frac{\Delta d^{T P} \alpha P_{T g}^{\operatorname{Pr} e}\left(1-d^{T}\right)\left(1-d^{P}\right)}{(1-\alpha) P^{T O}}
$$

This standardized expression is an approximation of the expected contribution of liquidity transfer per dollar of equity premium. The higher this ratio, the more important the role of liquidity transfer in deal economics.

How is bidder CAR influenced by the relative liquidities of parent versus target stock? Assuming the deal is consummated immediately after its announcement, the expected bidder abnormal return $E^{P}(C A R)$ is estimated, taking the expected net added value from (4) and dividing it by the pre-deal break-up valuation from expression (1):

$$
E^{P}(C A R)=\frac{\left\{\begin{array}{l}
\Delta d^{P}\left(V_{B P I}^{S A}+P_{T h}^{P r e} N^{T}\right) \\
+P_{T h}^{P r e} N^{T} \alpha \Delta d^{T P}\left(1-d^{P}\right) \\
-P_{T h}^{P r e} N^{T}\left[\left(\alpha-d^{P}\right)-\alpha\left(1-d^{P}\right)^{2}\right] \\
+P^{P r e m} N^{T}\left(\Delta d^{P}-d^{P}+\alpha\right) \\
-c_{T}
\end{array}\right\}}{\left(1-d^{P}\right) V_{B P I}^{S A}+\alpha\left(1-d^{P}\right)\left(1-\Delta d^{T P}+d^{P}\right) P_{T h}^{\text {Pre }} N^{T}}
$$

On the empirical side, bidder CAR is typically estimated with a method suggested by Malatesta (1983) and employed in BLL, which isolates the share of bidder abnormal returns

${ }^{5}$ For plausible values, the first $d^{P}$ partial derivative of expression (4) is negative. The condition for negativity is $\frac{V_{P R E}^{B / U}}{T V^{P} r e}<\frac{5-4 d^{P}}{1-d^{T}}$, which is met for toehold values greater than a fourth of the parent's value, assuming the parent stock liquidity discount is less than $25 \%$. 
due to its own underlying assets, by subtracting the appreciation of its toehold in target shares. The adjustment on bidder CAR suggested by BLL subtracts the percentage of value change represented from the toehold $\alpha$ in the target, according to the following formulations, which provide the empirical counterpart of expression (8):

$$
\text { Adjusted Bidder } C A R=\frac{\text { Bidder } \Delta(A M V)-a \times \text { Target } \triangle(A M V)}{\text { BidderPreBid }(M V)-a \times \text { Target PreBid }(M V)}
$$

where:

$$
\left.\begin{array}{c}
\text { Bidder } \triangle(A M V)=\text { Bidder pre-bid } M V \times \text { Bidder } C A R \\
\text { Target } \triangle(A M V)=\text { Target pre-bid } M V \times \text { Target } C A R
\end{array}\right\}
$$

In expression (10), $\Delta(A M V)$ represents the difference in abnormal market values $(A M V)$ for bidder and target, adjusted by their [T - 2] pre-bid market values $M V$.

Assuming a conservative zero expected long-run parent liquidity improvement $\left(\Delta d^{P}=0\right)$ upon deal announcement and adjusting (8) according to (9), (10) is simplified as follows:

$$
E_{a d j}^{P}\left(C A R_{0}\right)=\frac{\left\{\begin{array}{l}
\Delta d^{T P} N^{T} \alpha\left(1-d^{P}\right) \\
-P_{T h}^{P r e} N^{T}\left[\left(\alpha-d^{P}\right)-\alpha\left(1-d^{P}\right)^{2}\right] \\
-d^{P} P^{P r e m} N^{T} \\
-c_{T}
\end{array}\right\}}{\left(1-d^{P}\right) V_{B P I}^{S A}+\alpha\left(1-d^{P}\right)\left(1-\Delta d^{T P}+d^{P}\right) P_{T h}^{P r e} N^{T}}
$$

The first term on the nominator is the expected liquidity transferring in expression (5), depicting its positive theoretical relation with the parent's expected CAR. Notably, a nonlinear relation exists between $E_{a d j}^{P}\left(C A R_{0}\right)$ and both parent versus target pre-deal liquidity difference $\Delta T^{P}$ and pre-deal parent liquidity discount $d^{P}$. In fact, for positive parent stub values before the deal announcement, $C A R_{O}$ is a nonlinear function of the former, as can be seen from the first partial derivative with respect to liquidity difference estimated as

$$
\frac{\partial E_{a d j}^{P}\left(C A R_{0}\right)}{\partial \Delta d^{T P}}=\frac{\alpha \frac{V_{B P I}^{S A}}{N^{T} P_{T h}^{P r e}}+\alpha^{2}\left(1+d^{P}\right)-\frac{\left[\frac{\left(\alpha-d^{P}\right)}{\left(1-d^{P}\right)}-\alpha\right]}{N^{T} P_{T h}^{P r e}}}{\left[\frac{V_{B P I}^{S A}}{N^{T} P_{T h}^{P r e}}+\alpha\left(1-\Delta d^{T P}+d^{P}\right)\right]^{2}}
$$

The relation with pre-deal parent liquidity is also nonlinear. Employing L'Hôspital's rule, the partial derivative with respect to $d^{P}$ tends to the nonlinear function $\frac{2 \alpha-\frac{P^{P r e m}}{P_{T h}^{P r e}}}{\Delta d^{T P}-2 d^{P}-2}$. The subtracted term $d^{P} P^{\text {Prem }} N^{T}$ represents the depreciation on the bidder's capitalization following the full acquisition of the target on the premium paid due to its own liquidity discount. It is subtracted as a negative liquidity synergy from the bidder's market value.

Based on the above, the bidder CAR is nonlinearly related with its own stock liquidity and its margin of difference from its subsidiary target. However, the critical liquidity difference covariate is affected by a number of variables and can be endogenous. On the basis of the 
existing empirical findings (Bates et al. 2006; Lee and Chung 2013) a vector $\boldsymbol{X}$ of variables can affect bidder CAR, including target price run-up, relative size and book to market ratios, the target's leverage, the series of dummies reflecting the legal setting described above, the deal offer type, and the target's price. Hence, the empirical estimation can be performed through the following system of equations, instrumented via a matrix $\mathbf{I}$ of exogenous instruments, which in our calculation includes year dummies and liquidity risk (Perrakis and Zhong 2017):

$$
\left.\begin{array}{l}
E_{a d j}^{P}\left(C A R_{0}\right)=c+\beta_{1} d^{P}+\beta_{2} \frac{\Delta d^{T P}}{1-\beta_{3} \Delta d^{T P}}+\beta_{4} \Delta d^{T P}+\boldsymbol{\beta} \boldsymbol{X}+\boldsymbol{\gamma} \mathbf{I}+u \\
\Delta d^{T P}=\zeta \mathbf{X}+\boldsymbol{\kappa} \mathbf{I}+v
\end{array}\right\}
$$

\section{Empirical methods}

\subsection{Infrequent trading and liquidity proxies}

The sample of squeezed-out firms involves targets whose vast majority of shares are withheld from the controlling bidders, rendering their stock trading duly thin and infrequent. To estimate returns and the associated liquidity proxies under thin trading, the event study adjustment proposed by Maynes and Rumsey (1993) is undertaken. Besides thin trading, liquidity's notorious elusiveness (Kyle 1985) necessitates employing a variety of proxies to gauge both friction and immediacy cost for acquirer and target shares before and after a successful deal consummation. The daily price and volume data in the sample allows estimation of a variety of low frequency liquidity proxies to capture price impact, cost of trading, and trading activity. Price impact measures include Amihud's ILLIQ (Amihud 2002), which links trading volume with transaction cost in a manner related to Kyle's (1985) lambda, and Amivest (Cooper et al. 1985), a practitioners' favorite (Goyenko et al. 2009). Price impact is also measured with Gamma (Pastor and Stambaugh 2003), which estimates the regression coefficient of volume-driven return reversals. Nonparametric illiquidity measures, including run length (Das and Hanouna 2010), are also used in unreported robustness tests.

Cost-related measures include the relative spread (Amihud and Mendelson 1986), which is one of the simpler proxies, and Roll's impact (Roll 1984), which estimates the effective price spread based on the serial covariance of price changes. In addition, LOT (Lesmond et al. 1999) estimates the effective spread, breaking the sample up into informed and zero return non-informative days and FHT (Fong et al. 2011), which simplifies and improves LOT, albeit with a high correlation to Kyle's lambda. Trading activity is measured with the turnover ratio (Datar et al. 1998), based on the number of traded shares.

The proxies employed conclude with option-based models, including Longstaff and Schwartz (2001) upper bound of the opportunity cost for missing the ability to liquidate stocks in the market for both regularly and thinly traded stocks. Chacko et al.'s (2008) cost of immediacy, estimated under the extreme scenario of a bidder deciding to liquidate the entire target toehold in the marketplace, sets an alternative upper bound for liquidity cost. The return adjustments for thin trading are performed for those proxies involving stock returns. 


\subsection{Implied options calculation}

The moment the formal announcement of a bidding offer takes place, the value of the target stock in the trading session incorporates the option to participate in the cash or stock exchange. Following Bhagat et al. (1987), the prevailing market price $P_{M k t}^{F B}$ immediately following the bid announcement is constituted from the underlying theoretical value of the firm $P_{T h}^{F B}$ plus a put value $P^{P u t}$, which incorporates the offered terms:

$$
P_{M k t}^{F B}=P_{T h}^{F B}+(1-\alpha) P^{P u t}
$$

The factor $(1-\alpha)$ represents the percentage sought in the bid, namely the remaining non-toehold outstanding target shares. Two distinctive modeling approaches are pursued accordingly, distinctive for each of the exchange mediums offered. For cash offers, the existing literature (Bhagat et al. 1987; Sudarsanam and Sorwar 2010) assumes that volatility is nonstochastic, and the implied European put to sell the stock at the offered price is modeled based on the Black and Scholes (1973) formula.

In this paper, for cash offers, a stochastic volatility framework is performed following Heston and Nandi's (2000) assumption of a $\operatorname{GARCH}(1,1)$ underlying data generation process for the stock price plus interest and dividends. The price at time $t$ of a European put with strike price $K$ expiring at time $T$ on an underlying stock with price $P_{T h}^{F B}(t)$ is estimated employing the put-call parity and Heston and Nandi's (2000) price for a European call with stochastic volatility, as follows:

$$
P u t^{\text {Cash }}=\left\{\begin{array}{l}
-\frac{1}{2} P_{T h}^{F B}(t)+\frac{1}{2} K e^{-r(T-t)} \\
-\frac{1}{\pi} K e^{-r(T-t)} \int_{0}^{\infty} \operatorname{Re}\left[\frac{K^{-i \varphi} f^{*}(i \varphi)}{i \varphi}\right] d \varphi \\
+\frac{e^{-r(T-t)}}{\pi} \int_{0}^{\infty} \operatorname{Re}\left[\frac{K^{-i \varphi} f^{*}(i \varphi+1)}{i \varphi}\right] d \varphi
\end{array}\right\}
$$

where $f^{*}(\varphi)$ is the characteristic function. The estimation of the put price is performed recursively from the terminal values to the current asset price, employing numerical integration. The put price depends on the current stock underlying price $P_{T h}^{F B}(t)$ and its volatility path $h(t+\Delta)$, which is a function of current and lagged asset prices.

For stock offers, a Margrabe-type (1978) American exchange option is estimated for the additional benefit delivered from the parent to the target shareholders to deliver their stock and receive bidder shares. The formulation follows Bjerksund and Stensland (1993) for the evaluation of the right to exchange accruing to target shareholders. Assuming that, following the bidding announcement, the parent stock $P_{P a r}^{F B}$ and target's underlying value $P_{T h}^{F B}$ follow geometric Brownian motions, in an efficient market the value of the exchange option Put ${ }^{E x c h}$ at the time $t=0$ is derived as follows ${ }^{6}$ :

$$
\begin{aligned}
P u t^{E x c h} & =E_{0}^{*}\left[e^{-r t} g\left(P_{P a r}^{F B}(t), P_{T h}^{F B}(t), t\right)\right] \\
& =F\left(P_{T h}^{F B}, P_{P a r}^{F B}, r-d_{t g t}, T, d_{p a r}-d_{t g t}, \sigma_{12}^{2}\right)
\end{aligned}
$$

with $E_{0}^{*}[]$ denoting the risk-adjusted probability measures' expectation at time 0 , written as a function $F()$ of an American put option with strike price $P_{T h}^{F B}$; of the current underlying asset, which is the parent's price $P_{P a r}^{F B}$ times the offer's exchange ratio; of the riskless rate $r-d_{t g t}$, which is derived as the risk-free interest rate minus the target's dividend yield; of the time to

6 The reader is referred to Bjerksund and Stensland's (1993) paper for the analytic formulae. 
maturity $T$ until the offer's announced expiration date; of a risk-adjusted drift $d_{p a r}-d_{t g t}$; and of the volatility $\sigma_{12}^{2}$, estimated as the covariance between parent's and target's stock.

A conservative estimate of the target's value implied in the put plus underlying theoretical stock portfolio is derived. Exchange options become more expensive the lower the value of the asset exchanged and the higher the value of the asset received. In the pursued formulation, the less valuable target's theoretical underlying value is delivered against the more valuable parent's market value of the offered exchange ratio.

The method to estimate equity underlying value, adjusting market prices for the exchange or the cash offer implied options, is based on the formulation suggested by Bhagat et al. (1987). Because neither the underlying value nor its volatility is directly observable, an indirect estimation based on stock market prices which reflect the value of the portfolio of the put $P u t^{i}$ plus its underlying stock values is performed. Following Sudarsanam and Sorwar (2010), the following quadratic tolerance function is minimized, subject to a one cent price limit:

$$
\left(P_{M k t}^{F B}-P_{T h}^{F B}-(1-\alpha) P u t^{i}\right)^{2}=0 \text { with } i=\text { Cash, Exch }
$$

Our estimation method for cash deals is quite distinctive from Bhagat et al.'s (1987) or Sudarsanam and Sorwar's (2010). Their algorithm converges if the volatility of the derived underlying price's time series throughout the post announcement period is equal to the realized volatility before the deal announcement. This is the restriction we impose for algorithm convergence in exchange deals for the covariance between the underlying equity price and parent's stock. However, for cash offers, because volatility is estimated herein as a GARCH(1, 1) process with parameters estimated from the sequence of target market prices preceding the deal announcement, it should be mean reverting to the historical long-run variance. Hence, the $\operatorname{GARCH}(1,1)$ long-run variance parameters are maintained as in the period before the deal. Bhagat et al.'s (1987) constant volatility is relaxed and the mean reverting property of the underlying equity's volatility is utilized instead. The minimization objective is to find the minimum underlying price satisfying the tolerance function (21). Because volatility plays the role of a return risk premium in Heston and Nandi's (2000) formulation, minimizing the underlying stock price underlies the maximization of conditional volatility, albeit with the added restriction of reversion to its long-run mean.

The estimation algorithm minimizes the tolerance function for each trading day with a random search minimization algorithm which generates different starting points, one of which is the historical pre-announcement price and/or the realized volatility. The global nonzero minimum price is obtained by taking the lesser of all of the estimated minima derived from the random starting points within a fixed percentage neighborhood (Gilli and Schumann 2012). Of 22 deals, one of which is a short-form merger in cash and 21 of which are stock or mixed offers, the algorithm fails to converge in at least one of the three deal-window days. In these cases, the unadjusted for implied options market prices are employed for CAR estimation. Overall, the difference between the market price and the minimum underlying equity is expected to drive a wedge between the existing literature's reported target CAR and our more conservative option-adjusted estimates (OACAR).

\subsection{Probability of moneyness}

The moneyness of the estimated put option granted to the target's minority shareholders, i.e. the extent to which the offering price exceeds the target's underlying value on the offer's expiration date, is an important deal parameter (Borochin 2014). In acquisitions other than 
squeeze-outs, the higher the option's moneyness, the higher the market's expectations that minorities shall receive, in the deal's due course, reappraised premiums due to synergies or overbidding (Bhagat et al. 1987). However, synergies have a distinctively different role in squeeze-out deals. In Amihud et al. (2004) theoretical model for US freeze-outs, the deal concludes if the tender price exceeds by any positive margin the pre-offer target market price. The rule they propose for successful and efficient bid conclusion is to deliver to nontendering shareholders the maximum between the offering and pre-tender target's trading price. This rule suggests that a necessary and sufficient condition for successful squeeze-outs is the valuation of the target to acquirers to exceed bidding costs plus the value of the target under incumbent management. According to Amihud et al. (2004) rule, liquidity transfer can act as a catalyst for successful deals without a commensurate increase in the offered premium. Notwithstanding that for cash bids minority shareholders are entitled, through Delaware court fair valuation procedure, to any target-specific synergies, bidders do not need to include liquidity transfer. This is because any benefit dependent upon taking the company from public to private status or depending upon specific acquirer characteristics, such as stock liquidity, cannot be counted in Subramanian (2007). As a result, the presence of liquidity transfer synergy in cash offers should be associated with underbidding, i.e. the increased probability the offering price falls short of the target's underlying value driving the put option's moneyness Out of The Money (OTM).

Madan et al. (2008) develop a mathematical formulation for the distribution of a European put option's moneyness. According to their formulation, moneyness is defined as the put option price forwarded to its expiration date and divided by the similarly forwarded underlying stock price for a relative strike given by the original option's strike divided by the same forwarded underlying stock price. They derive it as the ratio of the estimated put price $P^{P u t}$ forwarded to the expiration date $T$ over the likewise forwarded strike, which for our purposes is the offering price $P^{T O}$, in a Black-Scholes-Merton framework. ${ }^{7}$ Their derivation assumes a process for the moneyness of a stock and the relative moneyness of the fixed strike over the forwarded theoretical time zero underlying stock value with dividend yield $q$ and prevailing interest rates $r$. The authors show that puts divided by their strike are distribution functions of their strikes and maturities. Employing the Black-Merton-Scholes formulation, the distribution of moneyness as a function of maturity, relativized by its strike, is derived as follows:

$$
\begin{aligned}
\frac{P^{\text {Put }}\left(\frac{P^{T O}}{P_{T h, 0}^{F B} e^{(r-q) T}}, T\right)}{\frac{P^{T O}}{P_{T h, 0}^{F B} e^{(r-q) T}}}= & N\left(\frac{\ln \frac{P^{T O}}{P_{T h, 0}^{F B} e^{(r-q) T}}}{\sigma \sqrt{T}}+\frac{\sigma \sqrt{T}}{2}\right) \\
& -\frac{1}{\frac{P^{T O}}{P_{T h, 0}^{F B} e^{(r-q) T}}} N\left(\frac{\ln \frac{P^{T O}}{P_{T h, 0}^{F B} e^{(r-q) T}}}{\sigma \sqrt{T}}-\frac{\sigma \sqrt{T}}{2}\right)
\end{aligned}
$$

Employing Madan et al. (2008) results, we use this probability distribution to estimate the moneyness process for the squeeze-out puts granted to minority shareholders. As can be seen from (18), overbids, i.e. higher $P^{T O}$ as a percentage of the underlying forwarded theoretical target value $P_{T h}^{F E}$, underlie a greater value for the shareholder put and an increased probability

\footnotetext{
7 Certain assumptions are required for the moneyness process. It has to be a positive local martingale under the risk neutral probability $P$ with respect to its natural filtration $F=\left(F_{t}, t \geq 0\right)$, to have no positive jumps, and to tend to zero at infinity. Readers can refer to Madan Roynette and Yor's (2008) original article for the mathematical derivations.
} 
the put gets In The Money (ITM). The degree to which liquidity transfer synergy can affect this probability is further examined. To the extent competitors, alongside other synergies, force the bidder to price it in the tender offer price, the probability of overbidding increases. However, in the case the bidder does not count liquidity transfer in, the tender offer price as a percentage of the underlying theoretical value should stay unaffected and the probability of overbidding is subdued.

\section{Data and summary statistics}

The freeze-out deals involving US listed gone private targets from worldwide listed parents between 1990 and the end of 2014 are identified using the SDC database. The search term applied is "acquisitions of remaining interest" for US listed targets. Acquisitions from private bidders are excluded, with the exception of those belonging to ultimately publicly quoted holding companies. Each deal announcement is individually examined through Edgar (the SEC website) to identify the specific details of the initial proposal, the dates and terms of any amendments, and other firm and deal characteristics, including outstanding shares, exchange ratio, and offer price. The SDC database list is also crosschecked with public sources (Dow Jones news) to establish the accuracy and sequence in the development of the public offer terms. After removing the uncompleted or withdrawn offers by the end of 2014, a sample of 162 freeze-outs is obtained. Annual accounting and daily price data for the listed companies are obtained from Bloomberg.

Table 1 summarizes for each of the 25 deal-years the total number of deals, broken down by those initiated from non-US listed parent ultimate holding companies, cash or stock offerings, and the days taken to complete the delisting. In the following columns several deal parameters are reported for both counterparties. The percentage of a target's shares in the parent's toehold and selected ratios, including the natural logarithm of market capitalization (Size), book to market value (BMV), and debt over equity (Debt/Equity), are estimated based on the 251-day average price in the period ending 42 trading days before the deal announcement ${ }^{8}$ and the most recent annual accounting data before the first offering's announcement.

The sample comprises, excluding the Genentech-Roche $\$ 40$ billion mega deal, an aggregate initial offer equity purchase consideration of $\$ 60.9$ billion. The summary statistics point to chronic subdued growth as a reason for parent companies taking their targets private (Bharath and Dittmar 2010). Equivalently, smaller target size (Bharath and Dittmar 2010) and lower leverage, hinting at free cash flow agency problems (Lehn and Poulsen 1989), drive parents to take their targets private. The ratio of cash to stock offerings is biased towards cash, with a ratio of $2-1$, in line with the squeeze-out literature (Subramanian 2007). Regarding bidder origin, cross-border freeze-outs represent only $23.3 \%$ of the deals, initiated from bidders directly or ultimately owned via non-US holding companies. The average parent toehold is $68 \%$ of the target's outstanding shares and the median equity consideration initially offered is $\$ 75.30$ million, amended $4 \%$ upwards to conclude the deal. Only ten cases include toeholds with a controlling interest of less than $50 \%$, three of them with less than $25 \%$. Eleven deals are short-form mergers with bidders holding more than $89.5 \%$ of the target before the transaction.

The liquidity characteristics of the counterparties are shown in Table 2 . The sample consists of duly illiquid targets relative to their acquirers, justifying the closer look at liquidity

8 This adjustment is in line with BLL's suggestion to control for the possibility of a higher ex-ante expectation of a forthcoming squeeze-out bid. 


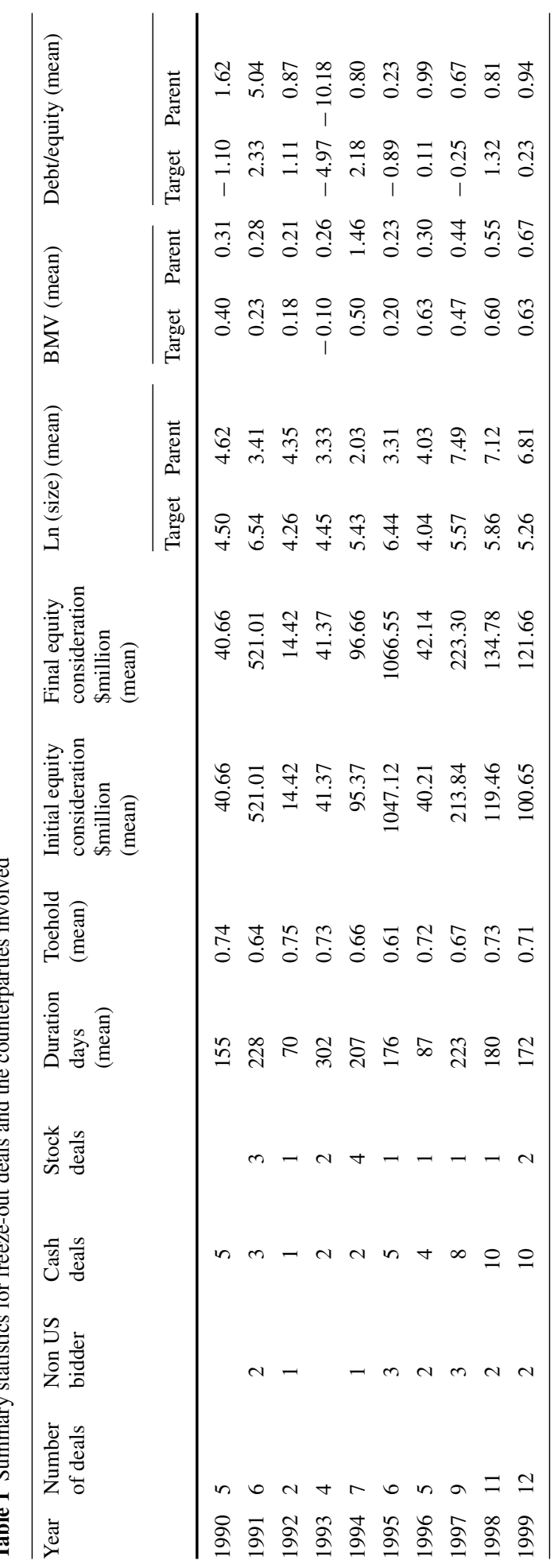




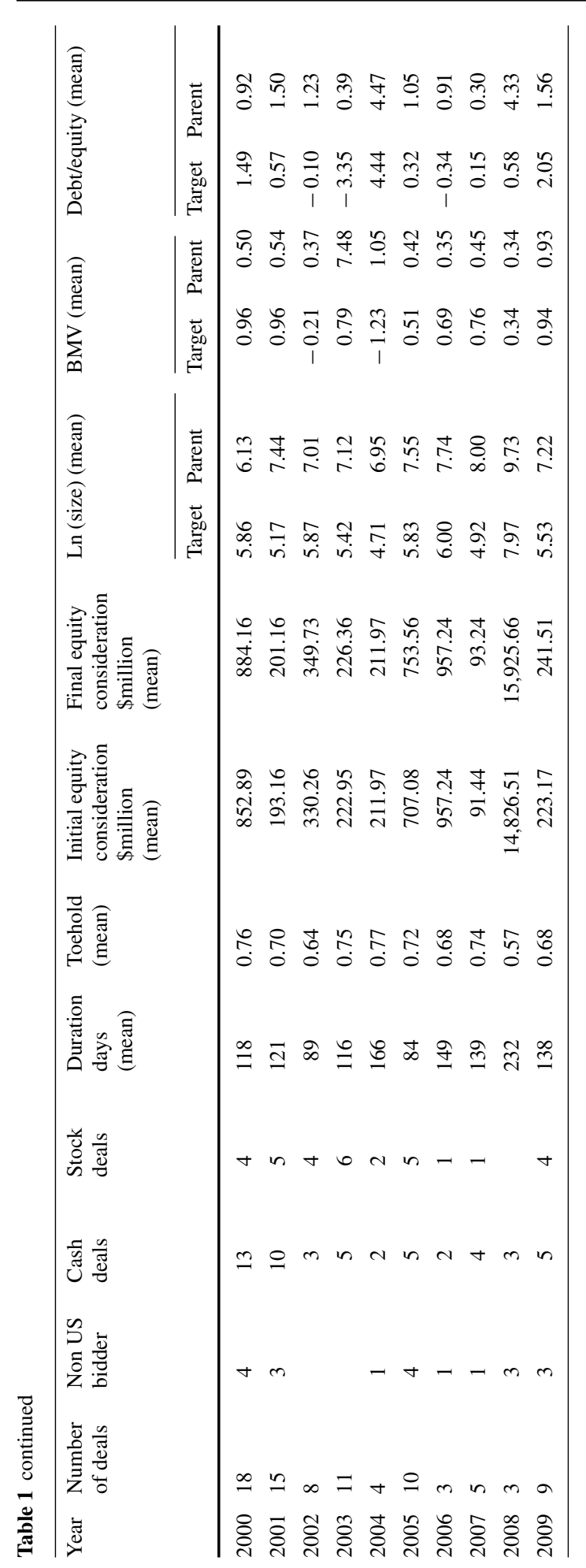




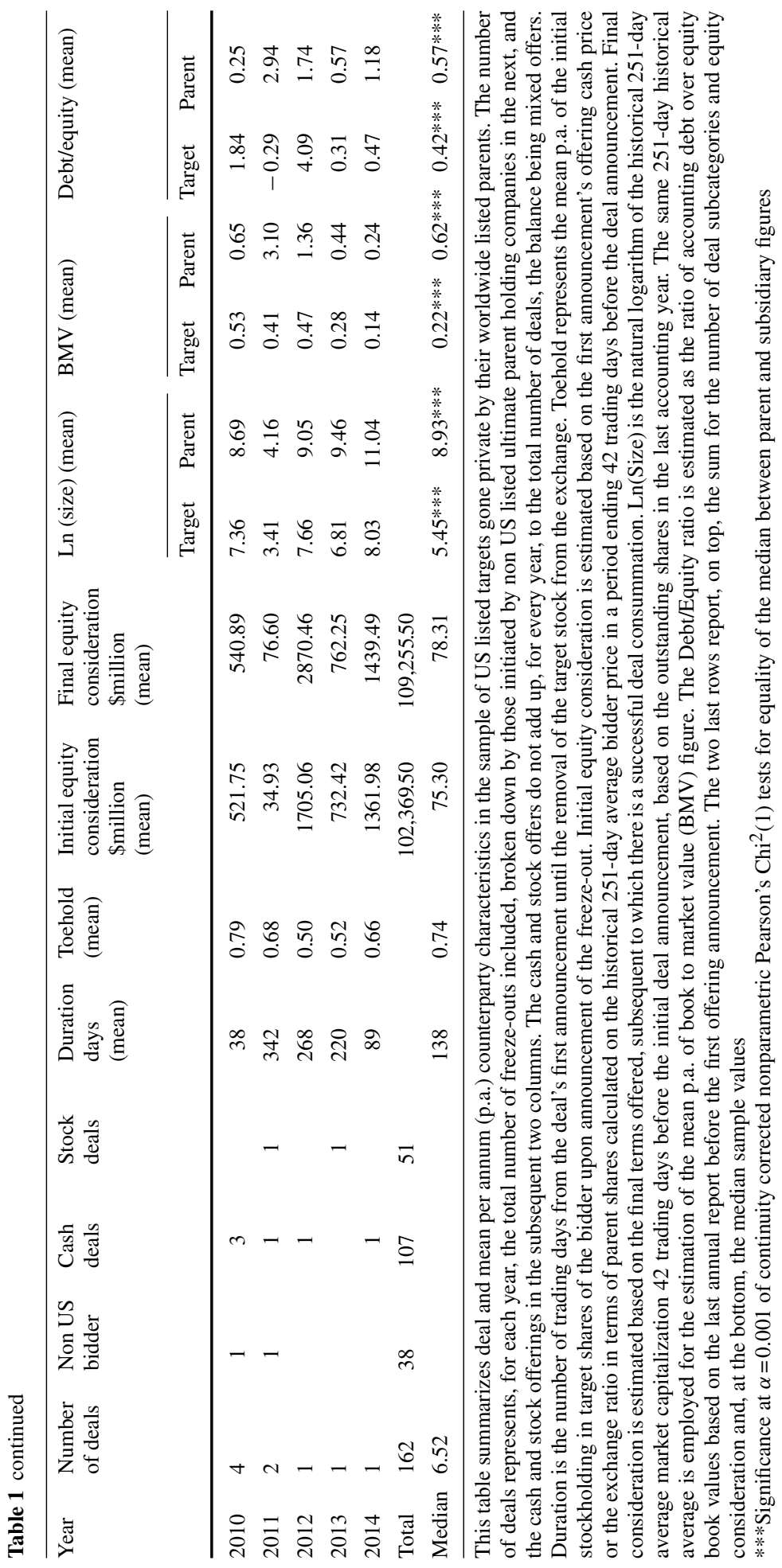


differences in successful bids. Approximately one in three bidder stocks exhibits some period of non-trading, eight of them missing more than 10 days in a 252-day trading year. The situation with the targets is more acute, with 145 firms, or $89.5 \%$ of the sample, experiencing some non-trading, two thirds of them missing in excess of ten trading days in a year. The mean target stock illiquidity before the deal announcement ranges from 1.26, for the LOT proxy, to 142.86, for the Amivest, times higher than its listed bidder's. This significant margin of liquidity disparity is reasonable for the majority of squeeze-outs involving parents already holding a substantial toehold in the target, alluding to a liquidity-driven downward sloping demand stock curve (Loderer and Jacobs 1995; Wurgler and Zhuravskaya 2002). An intensive discrepancy is also witnessed in comparing alternative liquidity proxies' historical volatility, which appears universally higher in the target. The ratio of target over parent illiquidity ranges from 1.65 to $87.34 .^{9}$ With very few exceptions, the liquidity proxies portray non-Gaussian distributions, mostly positively skewed with significant kurtosis. In unreported results, available from the authors upon request, the breakdown of liquidity proxy statistics by alternative deal offering type underlies no significant difference between cash and stock offers for the target versus parent illiquidity.

\section{Results}

\subsection{Liquidity transfer's magnitude and scarcity of target stock}

To make clear how important the added value derived from liquidity transfer is, we estimate its contribution for each specific deal via the standardized expression (7). In line with the existing literature, we resort to alternative liquidity proxies to help us ascertain the magnitude and direction of its influence. Mean and median statistics of the expected net value added from liquidity transfer for different liquidity proxies ${ }^{10}$ by offering type are reported in Table 3 . The estimated value of liquidity transfer is positive in the vast majority of the cases and for most liquidity proxies, including the small sample of mixed offers.

The point estimate for median liquidity transfer is positive and higher for cash offers. Its median contribution to parent value, measured with Chacko proxy, for stock and cash deals safely covers the 1.5 million average investment banking fees for equivalently sized US deals (Calomiris and Hitscherich 2007). Notably, in two cash and eight stock deals by RelSprd, and five cash and eleven stock deals by Chacko, liquidity transfer's estimated contribution sufficiently covers the initial premium offered, suggesting a decisive role in deal economics.

The stock market environment can be conducive to or prohibitive for generating value to the bidder via liquidity transfer. A critical factor is the prevalence of a downward sloping demand curve for the target's stock, evidence of a volume return relation (Loderer and Jacobs 1995; Shleifer 1986; Wurgler and Zhuravskaya 2002). Liquidity transfer's added value exists insofar as the demand curve flattens by shifting from the target's to the bidder's liquidity profile. A direct way to expose the existence of such a relation is to examine whether liquidity underlies the availability of shares in the market. In this case, bidders facing downward demand curves in the target's secondary market before a squeeze-out can increase target stock illiquidity by purchasing, i.e. removing, some additional target shares from the market. Even if the

9 The volatility ratio of target over parent Turno proxy, which measures liquidity, appears less than unity. However, with a Taylor expansion of the inverse Turno, the ratio of target over parent illiquidity is 3.25.

10 In unreported results, available from the authors upon request, only two of the liquidity transfer estimates with alternative liquidity proxies are strongly correlated, namely Amivest with Amih. 


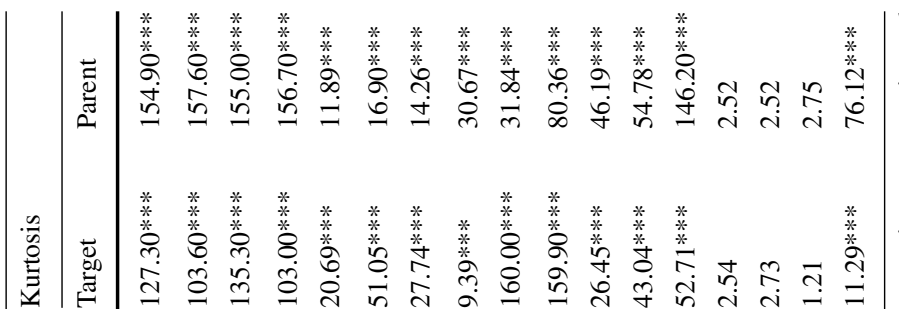

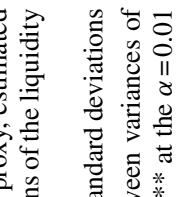

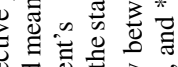

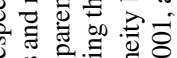

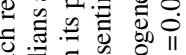

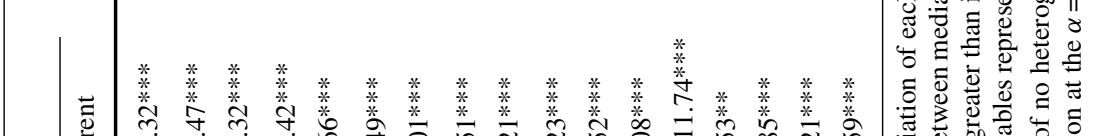

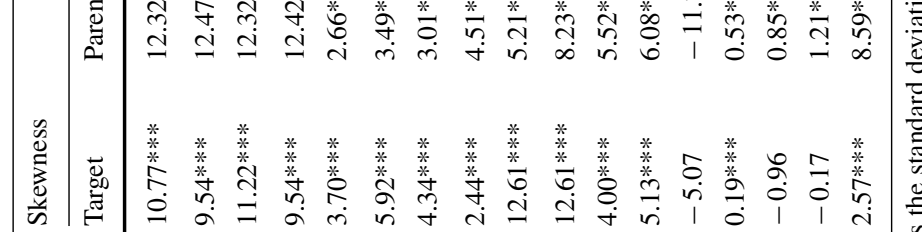
का कू

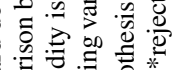

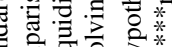

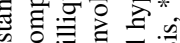

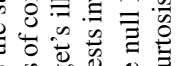

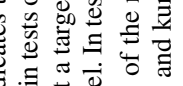

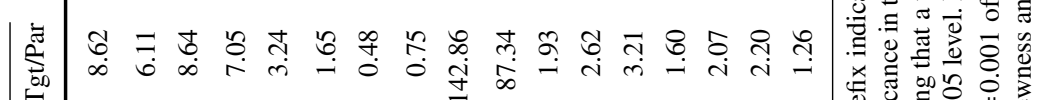

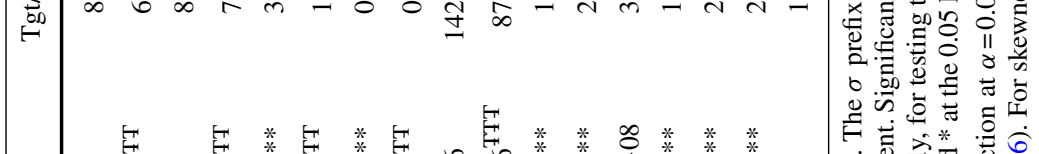

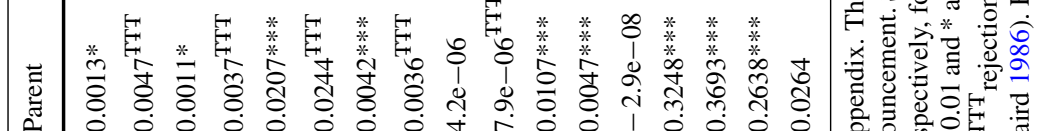

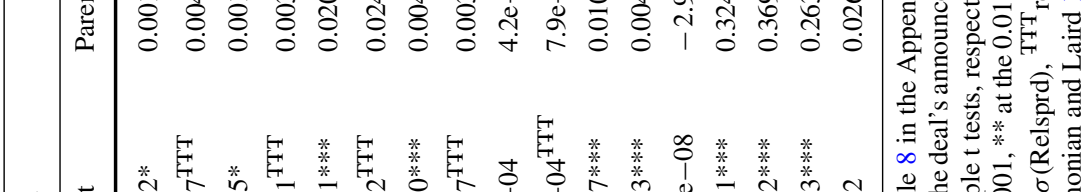

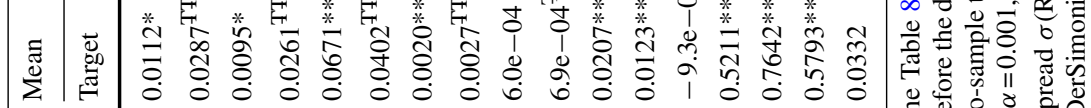

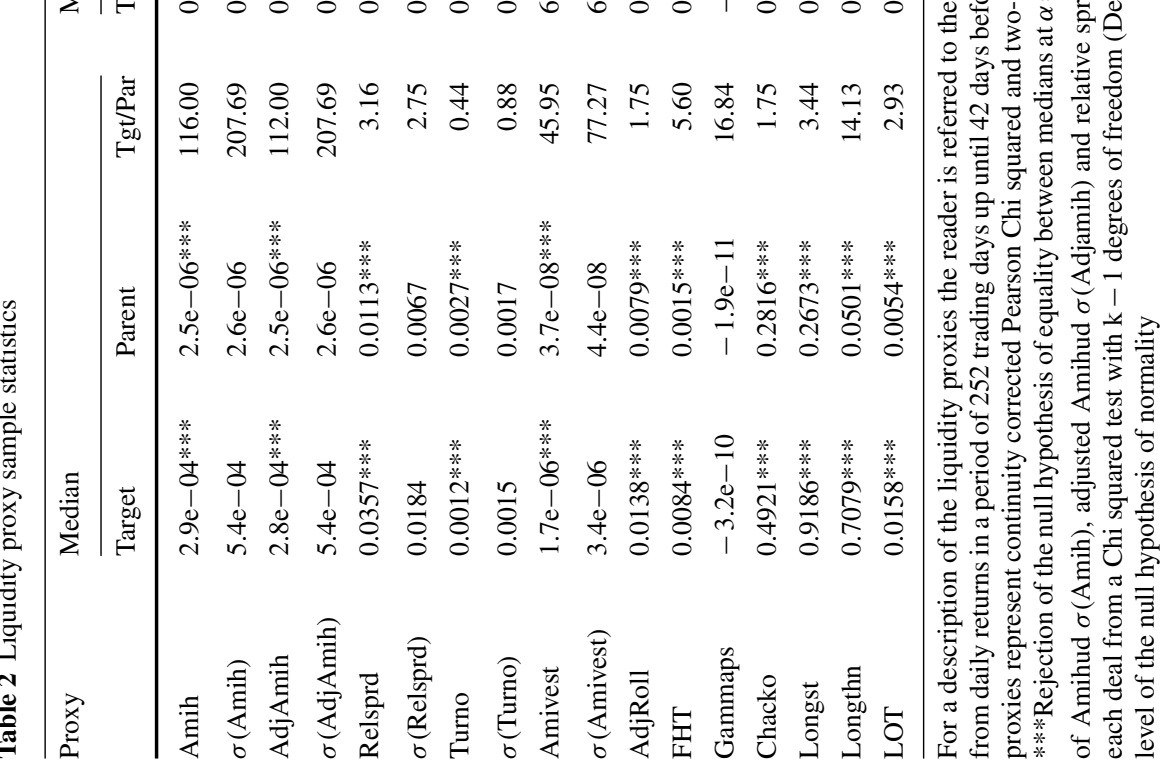




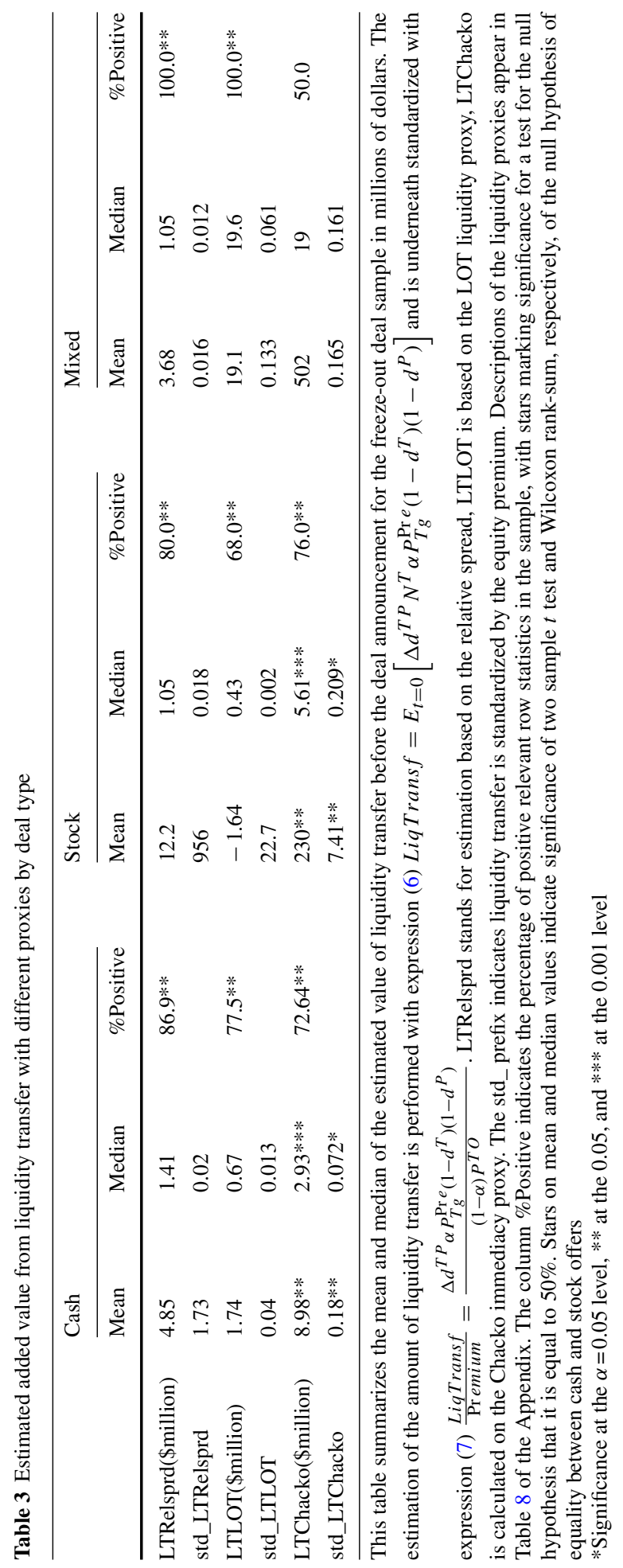


bidder's sole intention is to obtain a controlling toehold, higher target illiquidity means a cheaper stock if liquidity is priced. Both the added value derived from liquidity transfer and a favorable deal outcome, via the intimidation of prospective arbitrageurs, is facilitated.

Table 4 reports the results of simultaneous centile regressions for ten of the liquidity proxies between the two extreme 33 and $67 \%$ centiles, determined by target stock turnover, on the toehold. The two extreme centiles for every proxy are chosen to portray the differential impact of higher versus lower illiquidity on the parent. Should more illiquid targets, carrying a higher capacity to their acquirers from liquidity transferring, experience steeper demand curves, there is an obvious incentive to amass a higher toehold vis-à-vis an ultimate intention to freeze out. The regressions employ a number of control variables to minimize the effect of confounders and missing covariates. The relative book to market value of the target's over parent's stock (RELBMV), the debt to equity ratio (DBTEQ), the relative size between the bidder and the target (RELSIZE), a dummy for the years following the Siliconix decision (SILCX), a dummy for Thermo-Electron deals (THERMO), another for short-form mergers (SHFM), another for companies with negative equity (NEGEQ), a dummy for cash $(\mathrm{CASH}=1)$ or stock offers $(\mathrm{CASH}=0)$, and the natural logarithm of the deal duration in days are included. Results from 1000 Monte Carlo bootstrap resampling indicate that the option-based liquidity proxies Chacko and Lonsgt have a direct positive relation with the toehold size at a significance level of $\alpha=0.001$, and, marginally, Turno and AdjAmih at a $\alpha=0.10$ level. The point estimates for the toehold coefficient show a dependence of illiquidity on the amount of free-floating shares across liquidity proxies, with the exception of one proxy (FHT). Although only the Chacko proxy exhibits a statistically significant higher estimate of sensitivity with the toehold size in the more versus less illiquid centile, the majority of point estimates corroborate the inequality. Hence, this is fertile ground for affecting liquidity via reducing the availability of target shares.

The other source of liquidity synergies, according to our analysis, is the potential long-run improvement in acquirer stock liquidity. In unreported results, available from the authors upon request, median sample illiquidity improvement statistics support a statistically significant long-run improvement in parent liquidity across all deal types, stronger for stock offers. Our findings confirm a positive long-run effect of parent illiquidity improvement on bidder value and evidence that its anticipated positive synergy is factored into bidder price upon the deal's announcement.

\subsection{Generated Cumulative Abnormal Returns}

To analyze the economic rents generated on deal announcement, the implied option-adjusted underlying target's value CAR (OACAR) versus the non-adjusted values are compared to expose the utility of the suggested adjustment. The former registers the effects on the target's underlying equity of new information revealed about a bidder's offer relative to the target's fair value and the possibility of upward bid revision(s). The latter includes the claim that target shareholders have against the bidding firm derived from the put option offered. The discrepancy between the market CAR and OACAR, both estimated with Scholes-Williams betas, appears significant between the summary statistics reported on Table 5. The former register a positive mean and median target CAR of 14.54 and $11.61 \%$, while the optionadjusted statistics are 3.26 and $0.18 \%$, respectively. ${ }^{11}$ The equality between the observed and OACAR figures is rejected at the $\alpha=0.001$ level of significance, with nonparametric

11 Cases where there is either no convergence in the option adjustment algorithm or there is convergence to a degree not significantly different than zero underlying price at the $\alpha=0.05$ level are excluded. 


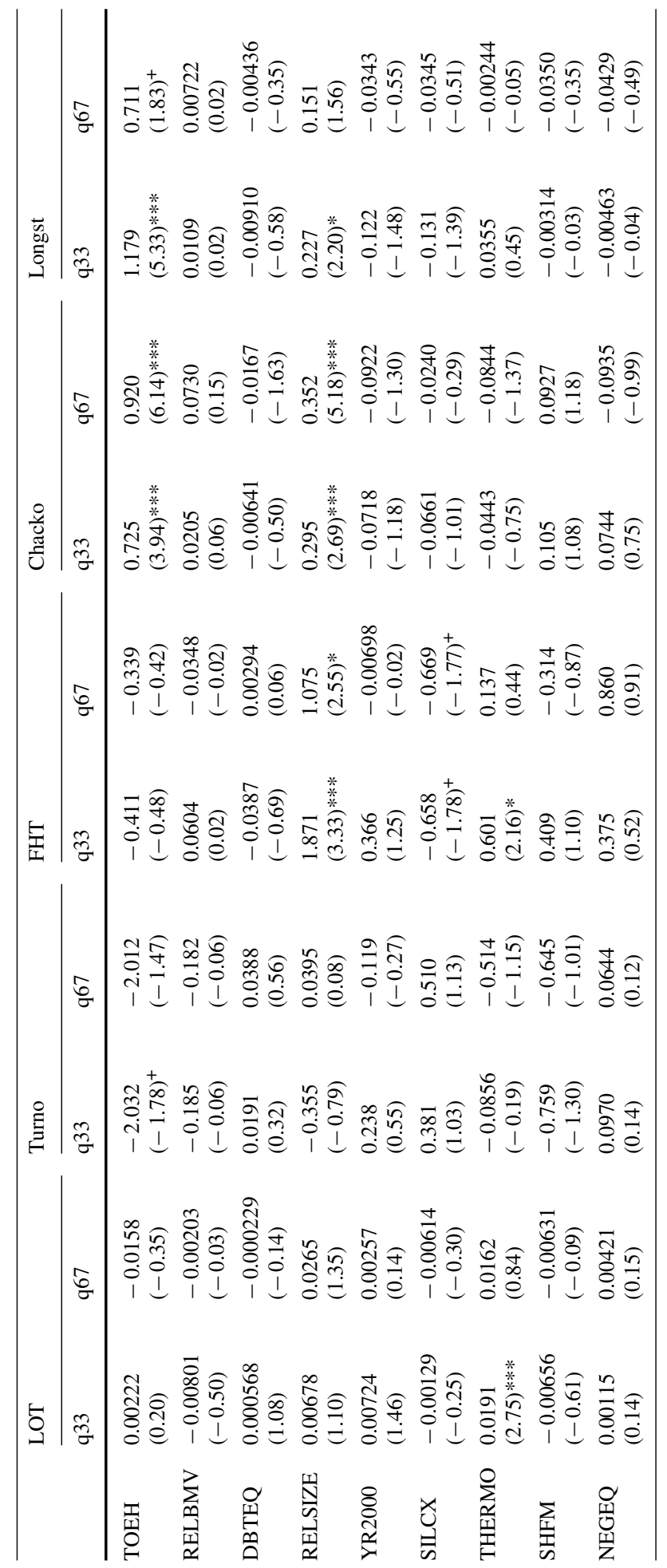




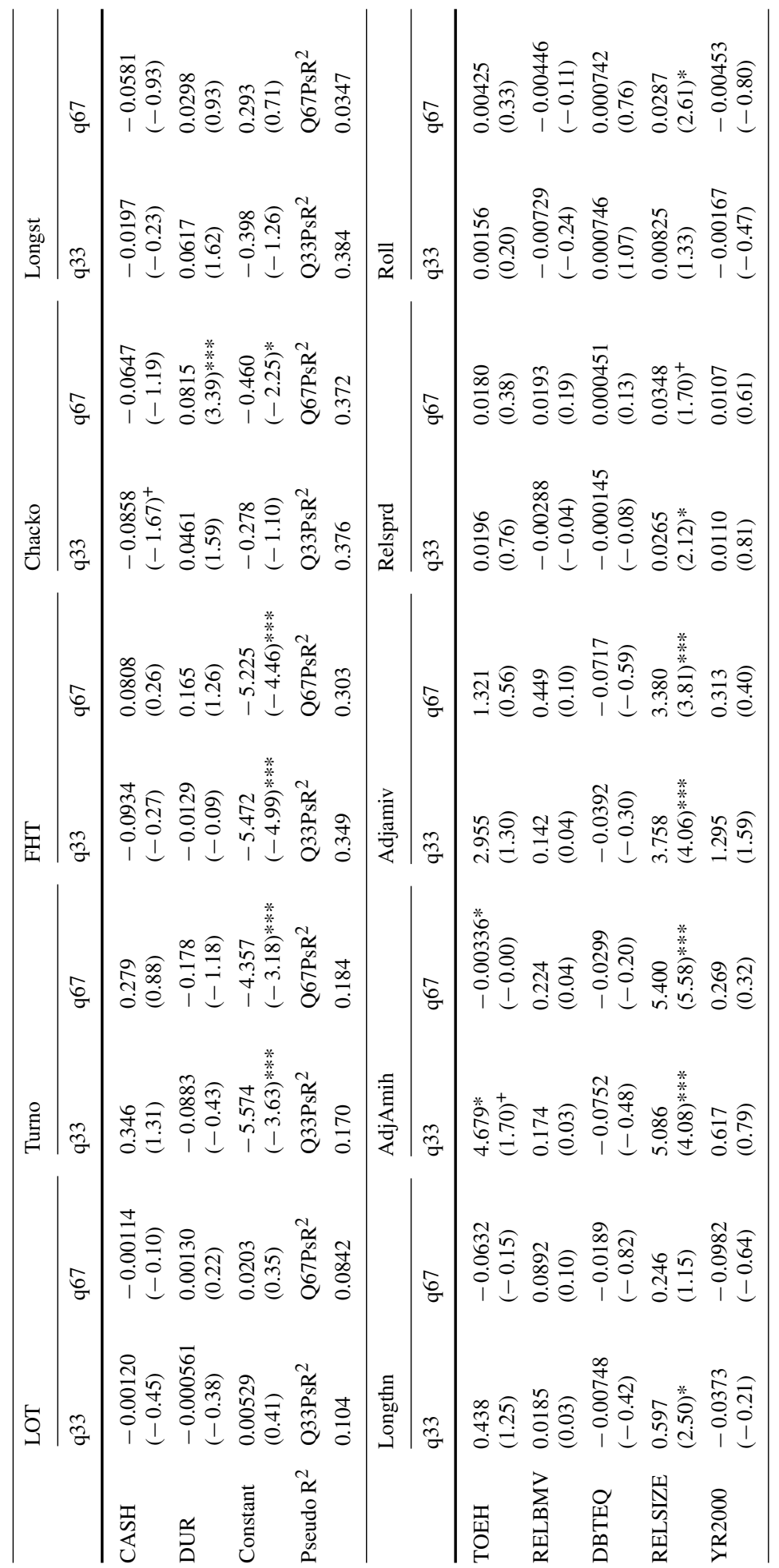




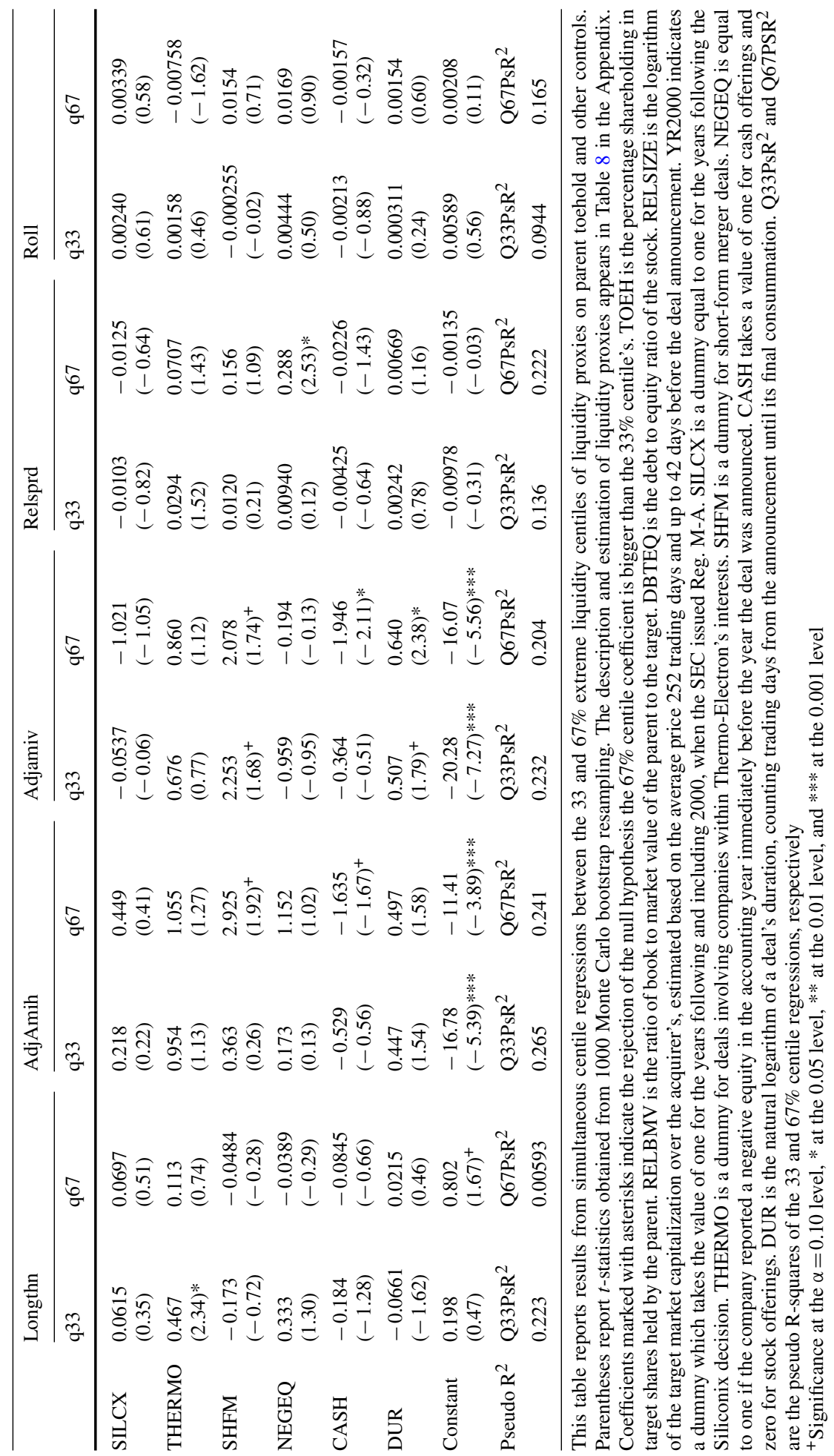




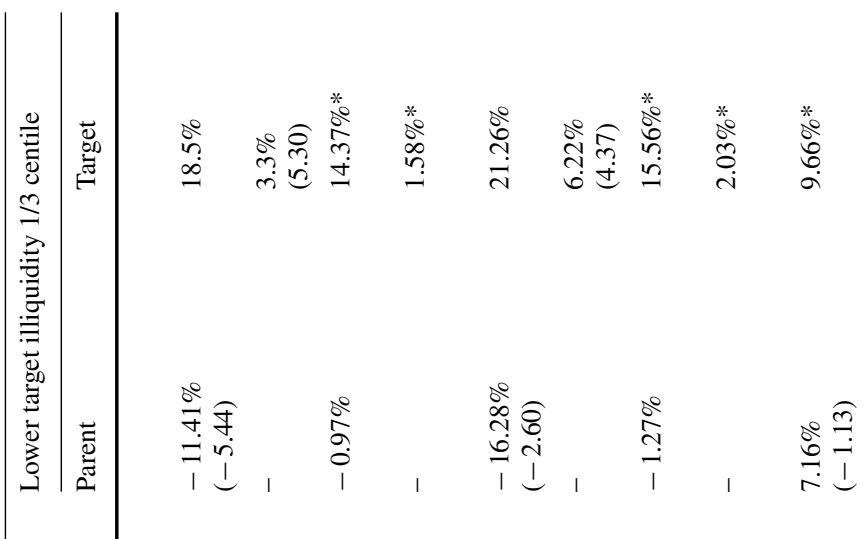

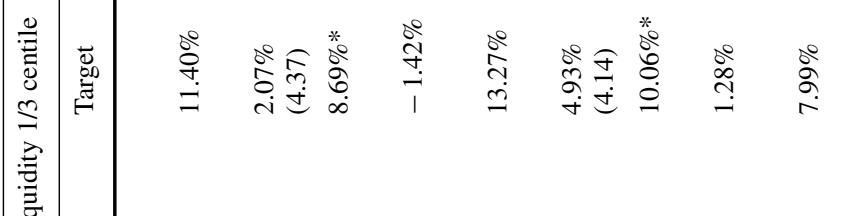

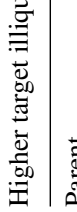

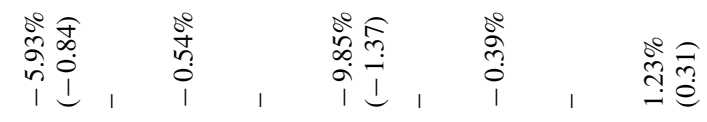

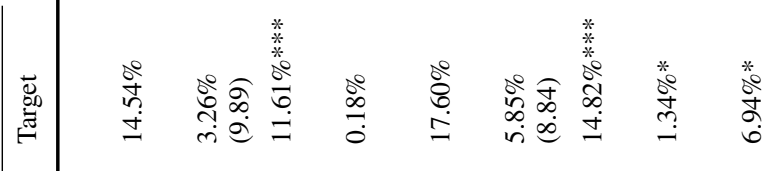

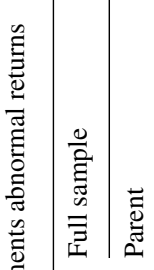

ì,

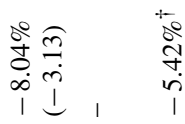

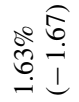

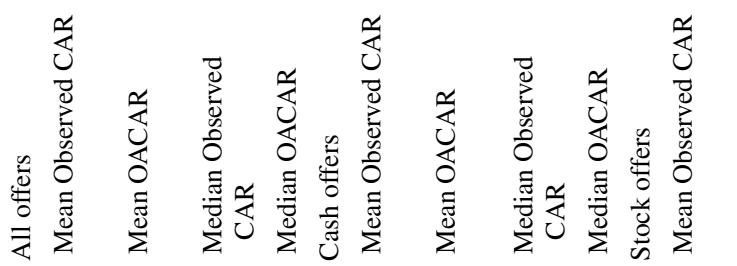




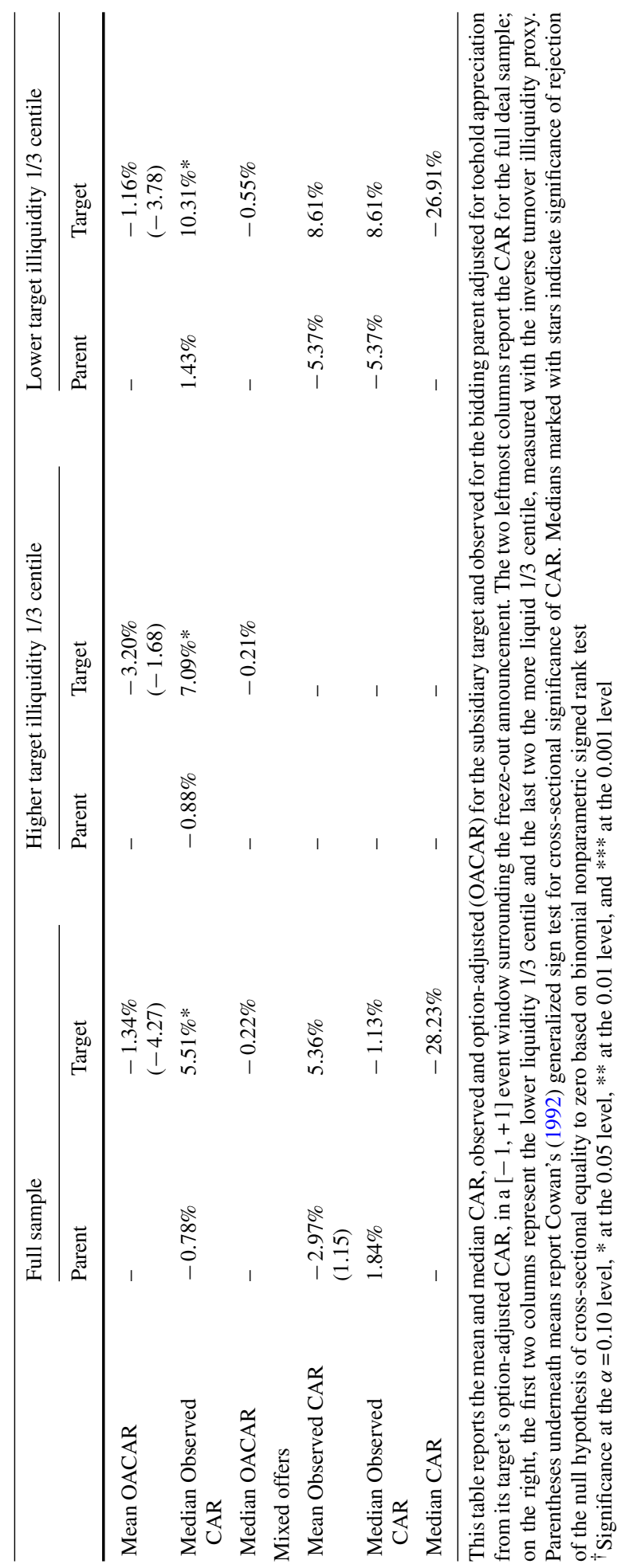


Wilcoxon signed-rank tests for the whole sample and the individual stock and cash deal subsamples. The apparent discrepancy between the two figures reveals the importance of the put option offered in squeeze-out economics, underlying more than $11.28 \%$ out of the $14.54 \%$ average target unadjusted CAR. Notably, the existing squeeze-out empirical literature (e.g. Bates et al. 2006; Lee and Chung 2013) mostly ignores this important implied options adjustment in estimating target CAR.

For the cross-sectional tests of CAR, Cowan's (1992) nonparametric sign test is conducted, as suggested by Maynes and Rumsey (1993), for interpreting the thin trading return adjustments. The average adjusted CAR for parent stock, employing Eq. (11), the empirical counterpart of Eq. (9), which excludes toehold appreciation due to the bid premium, is reported in the left column of Table 5. Bidder average adjusted CAR is negative $(-5.39 \%)$, but insignificantly different from zero, whereas the median is statistically significantly negative $(-0.74 \%)$. The wide variation between mean and median underlies a significant negative skewness in our US squeeze-out sample. A part of the adjusted bidder CAR is represented by the positive liquidity transfer synergies explained in Eq. (9). Although liquidity transfer can mitigate the market's negative reaction, it does not on average reverse the negative sign of bidder adjusted CAR, although it can still have an important positive contribution to bidder returns.

Similar to the existing findings of BLL and Lee and Chung (2013), squeeze-out targets in our sample register a statistically significant positive mean observed CAR of $14.54 \%$. However, the mean target OACAR amounts to less than a quarter of that, registering $3.26 \%$. The nearly $20 \%$ margin of difference between mean adjusted bidder CAR and target observed CAR is diminished by comparing medians and OACAR. In terms of medians, target CAR is $11.61 \%$ and OACAR is an insignificantly different than zero $0.18 \%$, rendering its margin from median-adjusted bidder CAR less than $1 \%$. Overall, both from the bidder and target side, we find compelling evidence for the dependence of market expected returns on toehold appreciation.

The table is further split by medium of exchange to test the disparity of bidder versus target abnormal returns between cash and stock deals. The higher the cash content, the lower the bidder returns and the greater the disparity between bidder and target CAR and OACAR. Stock offers exhibit a median negative $(-0.78 \%)$ bidder CAR, and median negative $(-0.22 \%)$ target OACAR, not significantly different from zero. Cash offers register a negative median bidder CAR, and a positive median $1.34 \%$ target OACAR, respectively. Mixed offers display a positive $1.84 \%$ median parent CAR and a median negative $(-28.23)$ target CAR. ${ }^{12}$ Overall, the market receives more positive cash deal announcements for targets versus bidders, and stock deals leave market participants indifferent irrespective of the medium offered The literature purports that the higher frequency of cash versus stock offers in squeeze-outs is either due to the fact that minority shareholders can receive cash more quickly (Subramanian 2007) or because bidders wish to signal their confidence in their assessment of target value (Fishman 1989) and the valuation of their own stock (Eckbo and Thorburn 2000). The optionadjusted analysis provides a straightforward ratification of the latter, pinpointing that cash bid higher median returns underlie target value rather than bidder inertia.

The target illiquidity can shed additional light on the drivers of abnormal returns. The sample is divided into three illiquidity centiles by target turnover ratio, with results, for the most illiquid, reported in the middle column, and for the most liquid, or least illiquid, in the right-hand column of Table 5. When comparing the centiles we see that the bidder median-adjusted CAR is not significantly different than zero for both target extreme illiquidity

12 OACAR is not estimated for mixed offers. 
samples. In contrast, the more liquid the target stock, the higher the target median OACAR, of $1.58 \%$ (versus $-1.42 \%$ ). Market participants expect an increased premium on freezeout announcements for more illiquid targets, although for bidders there is no statistically significantly different from zero abnormal announcement return. Hence, although bidders in squeeze-outs fail to capture the liquidity premium, in line with Massa and Xu's (2013) findings, market participants do not penalize them with negative returns, possibly due to liquidity transfer's contribution to bidder returns.

We next focus on the alternative means of payment between alternative target illiquidity centiles. The median OACAR of less liquid targets' shareholders is statistically significantly lower in cash offers only. This can underlie an expectation of a lower premium revision, due to the absence of arbitrageurs (Jindra and Walking 2004). However, the bidder's choice of stock versus cash is not returning statistically significantly different OACAR between illiquidity centiles, on the basis of a two sample nonparametric equality of medians test. However, in the most illiquid centile of target stock, the choice of stock is statistically significantly better received than cash, registering a positive $1.43 \%$ median CAR versus a negative $(-1.27 \%)$, at the $\alpha=0.05$ level.

Why does the market receive the announcement of stock offers for the most illiquid targets as better news for bidders than cash? Liquidity transfer in conjunction with bidder long-run liquidity can offer a plausible explanation. The value added for the bidder, on the basis of our theoretical analysis for liquidity transfer, increases for targets with a greater margin of stock liquidity difference, which, coupled with its potential to bridge information asymmetry in stock deals (Hansen 1987), can render equity the medium of choice.

To gauge the direct effects of target's illiquidity on bidder adjusted CAR, we report a series of Generalized Method of Moments (GMM) on the basis of Eq. (10) with alternative estimation methods ${ }^{13}$ in Table 6 . Liquidity and liquidity differences are estimated with all of the employed liquidity proxies, but are reported with only Amih and RelSprd liquidity proxies to save space, without qualitative differences. In the first two columns of Table 6, entitled Panel A, the iterative GMM results are reported, employing year dummies and liquidity risk, measured as the standard deviation of stock turnover ratio, as instruments.

In the next four columns, Panels B and C, results are based on the Taylor polynomial expansion of the nonlinear term included in Eq. (10):

$$
\alpha \frac{\Delta d^{T P}}{1-\beta \Delta d^{T P}} \simeq c_{1} \Delta d^{T P}+c_{2}\left(\Delta d^{T P}\right)^{2}+c_{3}\left(\Delta d^{T P}\right)^{3}+c_{4}\left(\Delta d^{T P}\right)^{4}
$$

The last two columns show results from the same formulation as in Panel B, with a reduced set of covariates to facilitate convergence, estimated with the continuously updated GMM or CUE of Hansen et al. (1996). The illiquidity difference between the target and its acquirer, and its nonlinear terms, appear to be a consistently significant factor in the GMM results, supporting the suggested nonlinear formulation (10). Across models, stock offers consistently deliver a lower parent CAR versus cash. Relatively smaller targets generate greater bidder CAR. Superior parent liquidity appears to deliver higher CAR to the bidder, in line with the posited effect of liquidity transfer in Hypothesis 1 . The estimated coefficients in the

\footnotetext{
13 Weak identification hampers nonlinear GMM estimators in samples of relatively smaller size (Stock et al. 2002). To overcome this difficulty and check the consistency of results, three alternative GMM approaches are pursued. First, an iterative formulation according to Eq. (10); second, a third-order Taylor expansion of the nonlinear term $\alpha \frac{\Delta d^{T P}}{1-\beta \Delta d^{T P}} \simeq c_{1} \Delta d^{T P}+c_{2}\left(\Delta d^{T P}\right)^{2}+c_{3}\left(\Delta d^{T P}\right)^{3}+c_{4}\left(\Delta d^{T P}\right)^{4}$ estimated with two-stage GMM; and third, a reduced form with the same Taylor expansion polynomial estimated with Hansen et al.'s (1996) continuously updated GMM estimator or CUE. Results for other liquidity proxies are consistent with reported findings and are available from the authors upon request.
} 
Table 6 GMM estimation of Parent CAR on illiquidity

\begin{tabular}{|c|c|c|c|c|c|c|}
\hline & $\begin{array}{l}\text { AdjAmih } \\
\text { Panel A }\end{array}$ & RelSprd & $\begin{array}{l}\text { AdjAmih } \\
\text { Panel B }\end{array}$ & RelSprd & $\begin{array}{l}\text { AdjAmih } \\
\text { Panel C }\end{array}$ & RelSprd \\
\hline \multicolumn{7}{|l|}{$E q: C A R^{P}$} \\
\hline$\Delta d^{T P}$ & $\begin{array}{l}0.0722 \\
(1.47)\end{array}$ & $\begin{array}{l}0.0930 \\
(0.67)\end{array}$ & $\begin{array}{l}0.0908 \\
(0.99)\end{array}$ & $\begin{array}{l}0.290 \\
(1.00)\end{array}$ & $\begin{array}{l}-0.128 \\
(-3.03) * * *\end{array}$ & $\begin{array}{l}0.217 \\
(2.41)^{*}\end{array}$ \\
\hline$\beta_{2}$ of $\left(\frac{\beta_{2} \Delta d^{T P}}{\left(1-\beta_{3} \Delta d^{T P}\right)}\right)$ & $\begin{array}{l}-0.468 \\
(-0.59)\end{array}$ & $\begin{array}{l}-0.340 \\
(-0.25)\end{array}$ & & & & \\
\hline$\beta_{3}$ of $\left(\frac{\beta_{2} \Delta d^{T P}}{\left(1-\beta_{3} \Delta d^{T P}\right)}\right)$ & $\begin{array}{l}-1.089 \\
(2.228)\end{array}$ & $\begin{array}{l}-2.354 \\
(0.272)\end{array}$ & & & & \\
\hline$d^{P}$ & $\begin{array}{l}0.07 \\
(-0.79)\end{array}$ & $\begin{array}{l}0.02 \\
(-4.33)^{* * * *}\end{array}$ & $\begin{array}{l}5.460 \\
(1.34)\end{array}$ & $\begin{array}{l}4.484 \\
(1.43)\end{array}$ & $\begin{array}{l}-1.586 \\
(-1.25)\end{array}$ & $\begin{array}{l}3.915 \\
(3.17)^{* * *}\end{array}$ \\
\hline$\left(\Delta d^{T P}\right)^{2}$ & & & $\begin{array}{l}-229.3 \\
(-0.22)\end{array}$ & $\begin{array}{l}-0.218 \\
(-3.10)^{* * *}\end{array}$ & $\begin{array}{l}-8143.5 \\
(-1.76)^{+}\end{array}$ & $\begin{array}{l}-0.129 \\
(-3.14)^{* * *}\end{array}$ \\
\hline$\left(\Delta d^{T P}\right)^{3}$ & & & $\begin{array}{l}1717.1 \\
(0.29)\end{array}$ & $\begin{array}{l}0.0279 \\
(0.57)\end{array}$ & $\begin{array}{l}45227.2 \\
(1.74)^{+}\end{array}$ & $\begin{array}{l}0.00223 \\
(0.08)\end{array}$ \\
\hline$\left(\Delta d^{T P}\right)^{4} N$ & & & $\begin{array}{l}-2978.1 \\
(-0.35)\end{array}$ & $\begin{array}{l}0.00289 \\
(0.27)\end{array}$ & $\begin{array}{l}-62228.0 \\
(-1.71)^{+}\end{array}$ & $\begin{array}{l}0.00469 \\
(0.80)\end{array}$ \\
\hline RELSIZE & $\begin{array}{l}-0.334 \\
(-1.47)\end{array}$ & $\begin{array}{l}-0.00532 \\
(-0.01)\end{array}$ & $\begin{array}{l}-0.117 \\
(-0.34)\end{array}$ & $\begin{array}{l}0.354 \\
(1.40)\end{array}$ & $\begin{array}{l}0.892 \\
(2.66)^{* * * *}\end{array}$ & $\begin{array}{l}-0.0637 \\
(-1.08)\end{array}$ \\
\hline RELBMV & $\begin{array}{l}0.00583 \\
(0.81)\end{array}$ & $\begin{array}{l}-0.00880 \\
(-0.04)\end{array}$ & $\begin{array}{l}0.00100 \\
(0.54)\end{array}$ & $\begin{array}{l}0.00148 \\
(0.54)\end{array}$ & & \\
\hline DBTEQ & $\begin{array}{l}-0.0188 \\
(-0.54)\end{array}$ & $\begin{array}{l}0.0474 \\
(0.39)\end{array}$ & $\begin{array}{l}-0.0243 \\
(-0.98)\end{array}$ & $\begin{array}{l}-0.0389 \\
(-1.23)\end{array}$ & & \\
\hline INVPRCE & $\begin{array}{l}-0.0203 \\
(-0.09)\end{array}$ & $\begin{array}{l}-0.220 \\
(-0.34)\end{array}$ & $\begin{array}{l}-0.102 \\
(-0.55)\end{array}$ & $\begin{array}{l}-0.488 \\
(-1.40)\end{array}$ & & \\
\hline NEGEQ & $\begin{array}{l}0.0873 \\
(0.34)\end{array}$ & $\begin{array}{l}0.274 \\
(0.18)\end{array}$ & $\begin{array}{l}-0.120 \\
(-0.98)\end{array}$ & $\begin{array}{l}-0.0714 \\
(-0.45)\end{array}$ & & \\
\hline SILCX & $\begin{array}{l}-0.108 \\
(-0.56)\end{array}$ & $\begin{array}{l}0.00750 \\
(0.02)\end{array}$ & $\begin{array}{l}-0.107 \\
(-1.03)\end{array}$ & $\begin{array}{l}0.238 \\
(1.02)\end{array}$ & & \\
\hline THERMO & $\begin{array}{l}0.0745 \\
(0.41)\end{array}$ & $\begin{array}{l}0.142 \\
(0.20)\end{array}$ & $\begin{array}{l}0.0735 \\
(0.78)\end{array}$ & $\begin{array}{l}0.104 \\
(0.79)\end{array}$ & & \\
\hline SHFM & $\begin{array}{l}-0.223 \\
(-0.35)\end{array}$ & $\begin{array}{l}-0.0458 \\
(-0.02)\end{array}$ & $\begin{array}{l}-0.274 \\
(-1.27)\end{array}$ & $\begin{array}{l}-0.0980 \\
(-0.33)\end{array}$ & & \\
\hline CASH & $\begin{array}{l}-0.157 \\
(-0.41)\end{array}$ & $\begin{array}{l}-0.124 \\
(-0.23)\end{array}$ & $\begin{array}{l}-0.277 \\
(-1.21)\end{array}$ & $\begin{array}{l}-0.273 \\
(-1.58)\end{array}$ & & \\
\hline DUR & $\begin{array}{l}-0.0599 \\
(-0.64)\end{array}$ & $\begin{array}{l}0.0289 \\
(0.04)\end{array}$ & $\begin{array}{l}-0.0644 \\
(-0.98)\end{array}$ & $\begin{array}{l}0.00238 \\
(0.04)\end{array}$ & & \\
\hline ARUNUP & $\begin{array}{l}-0.0452 \\
(-0.21)\end{array}$ & $\begin{array}{l}-0.380 \\
(-0.17)\end{array}$ & $\begin{array}{l}-0.104 \\
(-0.40)\end{array}$ & $\begin{array}{l}-0.297 \\
(-1.59)\end{array}$ & $\begin{array}{l}-0.481 \\
(-3.48)^{* * *}\end{array}$ & $\begin{array}{l}-0.0497 \\
(-1.41)\end{array}$ \\
\hline Constant & $\begin{array}{l}0.929 \\
(1.26)\end{array}$ & $\begin{array}{l}-0.0793 \\
(-0.03)\end{array}$ & $\begin{array}{l}0.321 \\
(0.67)\end{array}$ & $\begin{array}{l}-0.448 \\
(-0.97)\end{array}$ & $\begin{array}{l}-0.776 \\
(-2.30)^{*}\end{array}$ & $\begin{array}{l}-0.0449 \\
(-0.53)\end{array}$ \\
\hline
\end{tabular}


Table 6 continued

\begin{tabular}{|c|c|c|c|c|c|c|}
\hline & $\begin{array}{l}\text { AdjAmih } \\
\text { Panel A }\end{array}$ & RelSprd & $\begin{array}{l}\text { AdjAmih } \\
\text { Panel B }\end{array}$ & RelSprd & $\begin{array}{l}\text { AdjAmih } \\
\text { Panel C }\end{array}$ & RelSprd \\
\hline \multicolumn{7}{|l|}{$E q: \Delta d^{T P}$} \\
\hline RELSIZE & $\begin{array}{l}4.211 \\
(5.18)^{* * *}\end{array}$ & $\begin{array}{l}0.137 \\
(0.42)\end{array}$ & & & & \\
\hline DBTEQ & $\begin{array}{l}-0.0734 \\
(-0.28)\end{array}$ & $\begin{array}{l}-0.142 \\
(-1.22)\end{array}$ & & & & \\
\hline RELBMV & $\begin{array}{l}-0.0175 \\
(-0.48)\end{array}$ & $\begin{array}{l}0.0274 \\
(1.34)\end{array}$ & & & & \\
\hline INVPRCE & $\begin{array}{l}-0.652 \\
(-0.58)\end{array}$ & $\begin{array}{l}0.578 \\
(1.09)\end{array}$ & & & & \\
\hline$\sigma_{\text {TgtTurno }}$ & $\begin{array}{l}-355.1 \\
(-2.22)^{*}\end{array}$ & $\begin{array}{l}-110.1 \\
(-1.32)\end{array}$ & & & & \\
\hline Constant & $\begin{array}{l}-0.634 \\
(-0.59)\end{array}$ & $\begin{array}{l}1.273 \\
(3.06)^{* * *}\end{array}$ & & & & \\
\hline Hansen's J-statistic & 11.94 & 20.43 & & & & \\
\hline p_HanJ & & & 0.939 & 0.976 & 0.736 & 0.684 \\
\hline p_EndoC & & & 0.400 & 0.503 & 0.571 & 0.985 \\
\hline p_Redn & & & $0.0008 * * *$ & $0.00371 * *$ & $0.00149 * *$ & $0.00422 * *$ \\
\hline
\end{tabular}

This table reports coefficients from GMM estimation of the system of nonlinear equations of the parent-adjusted CAR on parent illiquidity and other covariates, and its difference from target stock on several covariates before the deal announcement. Panel A follows the nonlinear formulation (30) estimated with iterative GMM, Panel B employs a third-order Taylor expansion of the nonlinear term $\beta_{2} \frac{\Delta d^{T P}}{1-\beta_{3} \Delta d^{T P}} \simeq c_{1} \Delta d^{T P}+c_{2}\left(\Delta d^{T P}\right)^{2}+$ $c_{3}\left(\Delta d^{T P}\right)^{3}+c_{4}\left(\Delta d^{T P}\right)^{4}$ and the same covariates as in Panel A, estimated with two stages GMM, and Panel $\mathrm{C}$ reports results from estimating the Taylor polynomial formulation with continuously updated GMM estimator or CUE of Hansen et al. (1996), with fewer covariates to facilitate convergence. Year dummy variables are employed as instruments in every formulation. Each column lists the coefficients estimated, employing, from left to right AdjAmih and RelSprd to calculate target versus parent liquidity difference and parent illiquidity, the description of which can be found in the "Appendix". In Panel A, Eq: $C A R^{P}$ denotes the formulation $E^{P}\left(C A R_{0}\right)=c+\beta_{1} d^{P}+\beta_{2} \frac{\Delta d^{T P}}{1-\beta_{3} \Delta d^{T P}}+\beta_{4} \Delta d^{T P}+\boldsymbol{\beta} \boldsymbol{X}+\boldsymbol{\gamma} \mathbf{I}+u$ and Eq: $\Delta d^{T P}$ denotes $\Delta d^{T P}=\zeta \boldsymbol{X}+\kappa \mathbf{I}+v$ from expression (10). Row $\Delta d^{T P}$ reports the coefficient of the difference of target minus parent average stock illiquidity 252 trading days and up to 42 days before the deal announcement. $d^{P}$ is the parent liquidity discount and $\beta_{2}$ and $\beta_{3}$, each of the coefficients in the nonlinear expression $\beta_{2} \frac{\Delta d^{T P}}{1-\beta_{3} \Delta d^{T P}}$. Covariates RELBMV, RELSIZE, INVPRCE, DBTEQ, SILCX, THERMO, SHFM, NEGEQ, CASH, and DUR are described in Table 4. ARUNUP is the estimated bidder stock run-up 41 trading days before the deal announcement, adjusted for infrequent trading. $\sigma_{\text {TgtTurno }}$ is the coefficient of the standard deviation of the target stock's 252 trading days and up to 42 days before the deal announcement. The reported Hansen J-statistic of the test for over-identifying restrictions at the bottom of Panel A is not significant. Panel B reports the coefficients of the third-order Taylor polynomial expansion of the nonlinear term in expression (30) and the rest of the covariates listed in Panel A, estimated with two-stages GMM. At the bottom of the panel, the probability of accepting the null hypothesis of instrument validity, p_HanJ, from a Hansen's J test, of accepting the null of $\Delta d^{T P}$ endogeneity, p_EndoC, from a difference-in-Sargan statistic, and accepting the null hypothesis of instrument redundancy, p_Redn, are listed for each alternative specification. In Panel C, the coefficients from the CUE GMM estimation of the Taylor expansion formulation of the nonlinear model with reduced covariates are reported. The partial derivative of liquidity difference on parent CAR, based on the delta method, $\frac{\partial C A R^{P}}{\partial \triangle d^{T P}}$, is additionally reported

Coefficient t-statistics and z-statistics, for derivatives, are reported in parentheses, with ${ }^{+}$indicating significance at the $\alpha=0.10$ level, * at the 0.05 level, ** at the 0.01 level, and $* * *$ at the 0.001 level 
iterative, two-stage Taylor expansion and CUE GMM results consistently indicate that thinner illiquidity differences between the parent and its subsidiary drive statistically significant higher bidder CAR. This is indicated either through the significant negative coefficient of the nonlinear denominator $\beta_{3}$ in the full model in Panel $\mathrm{A}$, the negative squared illiquidity difference in the Taylor polynomial full model in Panel B, or the first partial derivative of illiquidity difference on parent CAR in the reduced Taylor expanded model in Panel C. Its negative effect supports Massa and Xu's (2013) findings of higher bidder CAR in acquisitions of listed versus unlisted firms, and its nonlinearity justifies our suggested theoretical formulation.

\subsection{Liquidity transfer and overbidding}

To clarify liquidity transfer's role on the market's assessment of the probability that a deal is over/underbid, a series of centile regressions are run, with the probability PROB ITM that market participants endogenously assign to the cash deal outcome as the dependent variable, and liquidity transfer as the independent variable. PROB ITM is estimated, as described in Sect. 3.3, following Madan et al. (2008) formulation. Centile regression is selected because of the nonlinear role liquidity transfer plays on the probability of upward bid revisions, modeled in Sect. 3.3 with the put getting more ITM, i.e. increasing its moneyness. Following Amihud et al. (2004) model, either a small or a large liquidity transfer can generate a successful deal outcome so long as the offer exceeds the pre-tender market price. Hence, we do not expect a linear relation between liquidity transfer and the probability that the put is ITM. Centile regression is run across alternative PROB ITM centiles to gauge liquidity transfer's impact for different probabilities.

For the sake of establishing a base case scenario, Table 7 lists results for the median ITM PROB regression. For robustness, a number of control variables are used, described in Sect. 5.1 above. In addition, a series of unreported regressions with alternative standardized liquidity transfer variables on the basis of a series of liquidity proxies give the same qualitative results.

Results from the median regression are reported on Table 7 . The median probability the put option gets in the money, assuming no liquidity transfer, is the regression constant 0.552 . The market expected Thermo-Electron freezout deals to have an increased probability of overbidding, at a 0.10 level of significance, in line with the upward revisions in one out of three Thermo-electron deals in the sample. Results show, as expected, liquidity transfer having an overall negative impact on the probability of overbidding.

As discussed in the first paragraph above, liquidity transfer is not expected to affect the probability of overbidding in a linear way. The nonlinear impact of liquidity transfer is clarified in Fig. 2, which compares the estimated coefficients of the liquidity transfer covariate across centile regressions for every sample centile, at an increasing 5\% step of the probability the option gets in the money. The top line represents the $95 \%$ confidence interval for the $5 \%$ PROB ITM sample centile regression, and the bottom line the same $95 \%$ confidence interval for the 95\% PROB ITM centile. Figure 2 indicates that for the lower PROB ITM centiles up to and including the $40 \%$ centile of PROB ITM equal to $12.5 \%$, coefficients are either not or barely significantly different from zero. Hence, liquidity transfer has no significant impact in deals for which the market assigns a lower probability of overbidding. For median to higher PROB ITM sample centiles, liquidity transfer has a clear negative impact on the probability of overbidding. According to Amihud et al. (2004) model, there is no requirement for upward bid revision or to bid higher if there is enough value to bidders to cover the deal cost plus the value of the firm under incumbent management. The reported regression coefficient 
Table 7 Median regression of the probability the option gets in the money (ITM)

\begin{tabular}{ll}
\hline & PROB ITM \\
\hline std_LTRelsprd & -0.0000152 \\
ARUNUP & $(-4.35)^{* * *}$ \\
& -0.299 \\
RELBMV & $(-1.34)$ \\
& 0.0058 \\
RELSIZE & $(0.18)$ \\
THERMO & 0.0156 \\
& $(0.19)$ \\
NEGEQ & 0.142 \\
& $(1.92)^{+}$ \\
SHFM & -0.0185 \\
& $(-0.22)$ \\
SILCX & -0.051 \\
INVPRCE & $(-0.66)$ \\
Constant & -0.00591 \\
N & $(-0.14)$ \\
\hline
\end{tabular}

This table reports coefficients from quantile regression of the probability the offered option to participate in a cash squeeze-out bid gets in the money, PROB ITM, until squeeze-out bid expiration on standardized liquidity transfer std_LTRelsprd, calculated with the relative spread liquidity proxy, which is described in the "Appendix", and covariates RELBMV, RELSIZE, INVPRCE, SILCX, THERMO, SHFM, NEGEQ, CASH, and ARUNUP, described in Table 4

Heteroscedasticity robust $t$-statistics are reported in parentheses, with ${ }^{+}$indicating significance at the $\alpha=0.10$ level, * at the 0.05 level, ** at the 0.01 level, and *** at the 0.001 level

point estimates in Fig. 2 show that liquidity transfer synergy drives prospective acquirers to successfully conclude their bids by overbidding less than their counterparts with lower liquidity transfer values. The coefficient point estimates allude to the role liquidity transfer synergy can play but only in deals with a higher potential for overbidding, exhibiting PROB ITM very close to or higher than the sample median.

\section{Conclusion}

This paper examines whether acquirers can earn superior abnormal returns by transferring their superior liquidity to less liquid targets taken private. The transfer of liquidity is posited as an additional synergy in mergers and acquisitions, stemming from the stock liquidity difference between the bidder and its target. This synergy is evaluated drawing on theoretical and empirical evidence from the squeeze-out stage of going private transactions. Assuming that liquidity is priced, an analysis is developed to account for the expected benefit accruing to a bidder's valuation from upgrading the liquidity of its toehold in illiquid target shares after removing them from the exchange. The value derived from the acquirer's superior bidder liquidity being transferred to the valuation of its toehold is factored into the decision to proceed with the squeeze-out. The estimated added value, stemming from liquidity transfer according 


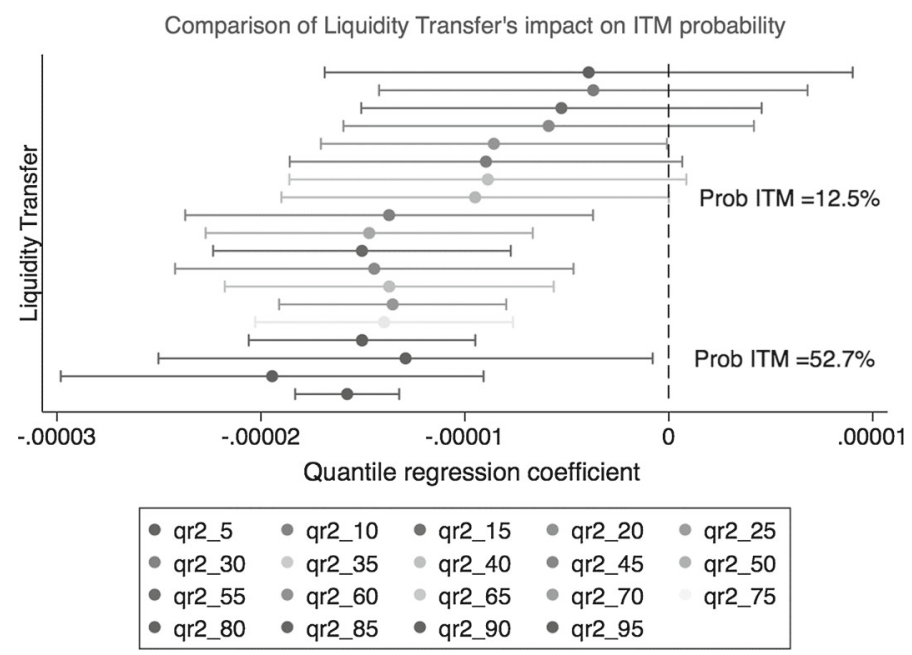

Fig. 2 Impact of liquidity transfer across sample centiles. Coefficients of PROB ITM centile regressions on liquidity transfer are shown in the figure, with coefficients from growing PROB ITM centiles from the top line (5\% PROB ITM centile, denoted as qr2_5 in the legend) to the bottom (95\% PROB ITM centile, denoted as qr2 95 in the legend). The estimated coefficient is the middle point of each line, and its $95 \%$ confidence interval extends through the line's width

to the existing SEC rules, escapes the entire fairness valuation rule, leaving room for bidders to avoid overbidding. This synergy, based on our theoretical analysis, depends on individual counterparty stock illiquidity and their liquidity differences, which in turn nonlinearly affect the expected cumulative abnormal returns and the reservation deal premium of prospective acquirers.

Because more illiquid targets can be taken private at a lower premium, due to the absence of arbitrageurs (Gomes 2001), the theoretically estimated added value from liquidity transfer can, in this case, benefit the acquirers more than squeezing-out firms with less illiquid stock. Empirical evidence from our sample of the entire freeze-out universe in the US markets initiated by globally listed acquirers between 1990 and 2014 not only shows that controllers' stock is many times more liquid than their subsidiaries' before the deal announcement but also that toehold size influences target illiquidity. Estimations take into account the infrequent trading witnessed in the sample, and relevant liquidity proxies are accordingly adjusted for trade-to-trade returns (Maynes and Rumsey 1993), an adjustment missing from the relevant squeeze-out literature, including Bates et al. (2006) and Cheung et al. (2015). The median estimated liquidity transferring synergy can amount to up to $20.9 \%$ in stock and $7.2 \%$ in cash offer deal premiums, with a positive contribution in $72.6 \%$ of the deals and a median value of $\$ 2.93$ million, on the basis of Chacko et al. (2008) liquidity proxy. In the US market environment, prospective acquirers, controlling sizeable toeholds of their targets, enjoy an advantageous downward sloping stock demand curve environment, which supports thinner stock market trading for their target (Lin et al. 2009). The extent to which self-dealing bidders can increase targets' illiquidity by buying additional stock, extracting a disproportionate share of the deal's generated wealth, is left for future research.

To correctly interpret deal generated wealth, target cumulative abnormal returns are estimated by subtracting from market prices the attached option to participate in the squeeze-out offer. The option-adjusted minimum target CAR (OACAR) is estimated based on a novel method employing Heston and Nandi's (2000) stochastic volatility frame- 
work for cash, alongside Bjerksund and Stensland's (1993) method for stock exchange offers. This methodological improvement can cast additional light on the cash offerings literature, which to date largely relies on non-stochastic volatility to estimate the underlying target's theoretical equity value (Bhagat et al. 1987). This is an area for future research.

Empirical results show that parent bid announcement CAR is significantly higher in deals with more liquid parents and more illiquid targets, in which targets exhibit lower OACAR. The theoretically proposed nonlinear relation of parent CAR, adjusted for its toehold appreciation, with liquidity differences between target and bidder stock, is confirmed, becoming more positive the more pronounced their illiquidity difference. Target OACAR is higher in cash versus stock offers, underlying value driven motives behind the selection of exchange medium (Fishman 1989; Eckbo and Thorburn 2000). Evidence that more illiquid targets are received as better news in the market for bidders in cash than for stock is provided, which portrays an impounded liquidity transfer synergy, coupled with a long-run liquidity improvement in parents' stock. The relatively more positive market reaction to bidder CAR for relatively more illiquid targets can be partly attributed to the direct effect of liquidity transfer and partly to the expectation of longer-run illiquidity improvement following a successful freezeout.

The extent to which the offering price exceeds the target's underlying value upon the offer's expiration date is an important deal parameter (Borochin 2014). We develop a new methodology to estimate the probability that the put option granted to the target's minority shareholders gets In The Money, i.e. its "moneyness," and facilitate the associated probability of underbidding. The implied probability of moneyness is derived from the estimated put option offered to target shareholders, employing a distribution of moneyness suggested by Madan et al. (2008). The extension of our method to corporate finance deals in relevant contexts is left to future researchers. On this basis, additional insights are gained on the role of liquidity transfer in deal economics. It is shown to nonlinearly affect the market's assessment of the probability that bidders overbid, playing no role in deals in which market consensus assigns a lower than median probability of overbidding, while strongly influencing those with median and above median probability assessments. In the latter, higher liquidity transfer synergy is associated with a lower probability of overbidding, underlying Amihud et al. (2004) freeze-out model, which suggests that a small positive value margin can ensure bidding success. Bidders with the benefit of liquidity transfer can complete deals without commensurately raising premiums, because liquidity transfer is not estimated in court fair valuation. The nonlinearity of liquidity transfer's influence can not only act as a catalyst for a favorable-to-bidder outcome but also a less expensive one, to the extent it cannot get adjudicated. A more detailed analysis of the legal ramifications is left for future researchers.

Open Access This article is distributed under the terms of the Creative Commons Attribution 4.0 International License (http://creativecommons.org/licenses/by/4.0/), which permits unrestricted use, distribution, and reproduction in any medium, provided you give appropriate credit to the original author(s) and the source, provide a link to the Creative Commons license, and indicate if changes were made.

\section{Appendix}

See Table 8 . 
Table 8 Description of liquidity proxies

\begin{tabular}{|c|c|}
\hline Liquidity proxy & Description \\
\hline Amih, AdjAmih & 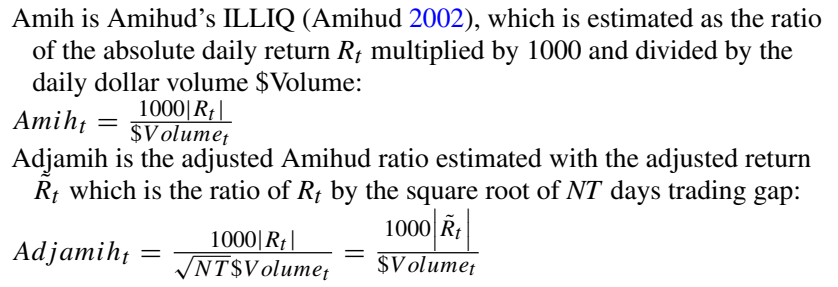 \\
\hline Relsprd & $\begin{array}{l}\text { Relsprd is the relative spread estimated as the closing day bid-ask spread } \\
\text { divided by the stock price: } \\
\text { Relsprd }=\frac{\text { Ask-Bid }}{\text { Price }}\end{array}$ \\
\hline Turno & $\begin{array}{l}\text { Turno is the turnover ratio estimated as the daily shares volume divided by } \\
\text { the total number of the company's outstanding shares: } \\
\text { Turno } t=\frac{\text { Volume }_{t}}{\text { OutstandingShares }}\end{array}$ \\
\hline Amivest & $\begin{array}{l}\text { Amivest is the inverse Amivest ratio (Datar et al. 1998), estimated as the } \\
\text { daily adjusted for infrequent trading absolute return multiplied by } 1000 \\
\text { and divided by the number of shares traded daily: } \\
\text { Amivest }_{t}=\frac{1000\left|\tilde{R}_{t}\right|}{\text { Volume }_{t}}\end{array}$ \\
\hline AdjRoll & $\begin{array}{l}\text { This is the Roll (1984) measure adjusted for non-negative price covariance } \\
\text { (Harris 1990) and non-trading days: } \\
\text { Adjroll }_{t}= \begin{cases}2 \sqrt{-\operatorname{Cov}\left(\tilde{R}_{t}, \tilde{R}_{t-1}\right)} & \text { if } \operatorname{Cov}\left(\tilde{R}_{t}, \tilde{R}_{t-1}\right)<0 \\
2 \sqrt{\operatorname{Cov}\left(\tilde{R}_{t}, \tilde{R}_{t-1}\right)} & \text { if } \operatorname{Cov}\left(\tilde{R}_{t}, \tilde{R}_{t-1}\right) \geq 0\end{cases} \end{array}$ \\
\hline Gammaps & $\begin{array}{l}\text { Pastor and Stambaugh (2003) Gamma adjusted for non-trading is derived } \\
\text { from the regression of excess returns over the CRSP value-weighted } \\
\text { index returns } \widetilde{R M}_{t} \text {, adjusted for thin trading, on daily dollar volume: } \\
\tilde{R}_{t+1}+\widetilde{R M}_{t+1}=\theta+\varphi \tilde{R}_{t}+\left(\text { Gamma }_{t}\right) \text { sign }\left[\tilde{R}_{t}\right] \$ \text { Volume }_{t}+\varepsilon_{t}\end{array}$ \\
\hline LOT & $\begin{array}{l}\text { Goyenko et al.'s (2009) modification of the original Lesmond et al. (1999) } \\
\text { LOT measure is employed, which breaks down the maximization of } \\
\text { likelihood space on the basis of stock, not index, returns. It calculates the } \\
\text { implied difference between the costs of buying minus selling a stock. } \\
\text { After adjusting returns for non-trading days it is estimated as follows: } \\
L O T=\alpha_{2 j}-\alpha_{1 j} \\
\text { where: } \\
\tilde{R}_{t}=\tilde{R}_{t}^{*}-\alpha_{1 j} \text { for } \tilde{R}_{t}^{*}<\alpha_{1 j} \\
\tilde{R}_{t}=\tilde{R}_{t}^{*} \text { for } \alpha_{1 j}<\tilde{R}_{t}^{*}<\alpha_{2 j} \\
\tilde{R}_{t}=\tilde{R}_{t}^{*}-\alpha_{2 j} \text { for } \alpha_{2 j}<\tilde{R}_{t}^{*}\end{array}$ \\
\hline FHT & $\begin{array}{l}\text { Employed in research analysis of very illiquid markets (Marshall et al. } \\
\text { 2013), it is estimated based on Fong et al. (2011), with the proportion of } \\
\text { zero stock returns } z \text { and the standard deviation of adjusted daily returns } \sigma \text { : } \\
F H T=2 \sigma N^{-1}\left(\frac{1+z}{2}\right)\end{array}$ \\
\hline
\end{tabular}


Table 8 continued

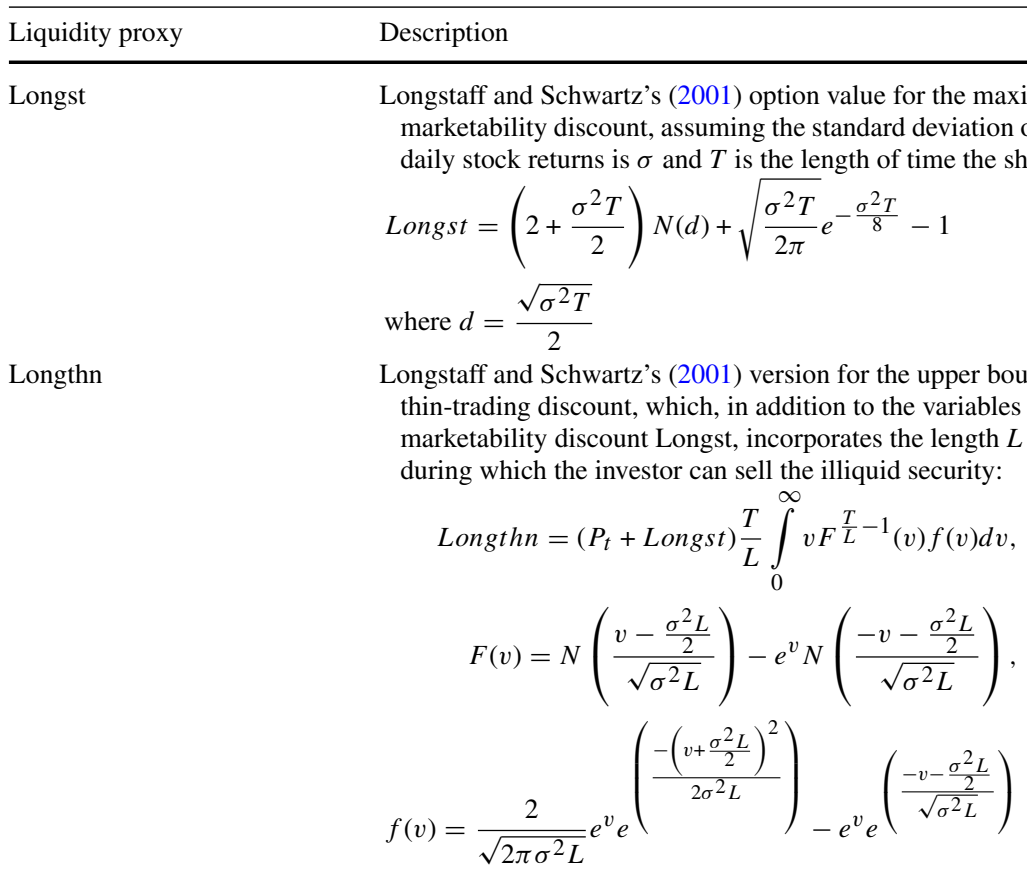

Chacko

Chacko et al. (2008) derive the cost of purchasing (+) or liquidating (-) securities under a prevailing riskless rate $r$, security return volatility $\sigma$ and expected waiting time $\frac{1}{\lambda\left(\frac{S}{B}\right)(Q)}$ for the completion of an order with size $Q$ as follows:

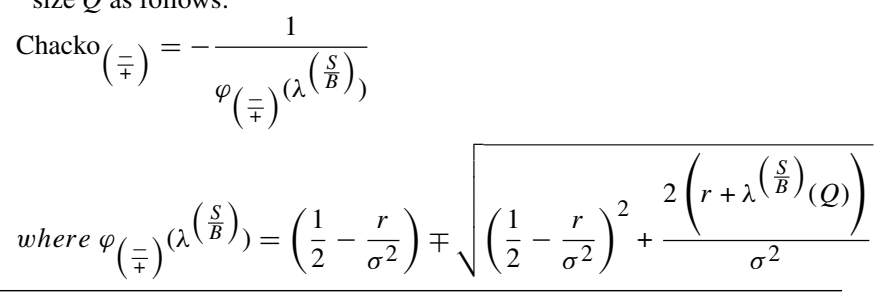

\section{References}

Amihud, Y. (2002). Illiquidity and stock returns: Cross section and time-series effects. Journal of Financial Markets, 5, 31-56.

Amihud, Y., Kahan, M., \& Sundaram, R. K. (2004). The foundations of freezeout laws in takeovers. The Journal of Finance, 59, 1325-1344.

Amihud, Y., \& Mendelson, H. (1986). Asset pricing and bid-ask spread. Journal of Financial Economics, 17, 223-249.

Andrade, G., Mitchell, M., \& Stafford, E. (2001). New evidence and perspectives on mergers. Journal of Economic Perspectives, 15, 103-120.

Baron, D. P. (1983). Tender offers and management resistance. Journal of Finance, 38, 813-827.

Bates, T. W., Lemmon, M. L., \& Linck, J. S. (2006). Shareholder wealth effects and bid negotiation in freeze-out deals: Are minority shareholders left out in the cold? Journal of Financial Economics, 81(3), 681-708.

Betton, S., Eckbo, B. E., \& Thorburn, K. S. (2009). Merger negotiations and the toehold puzzle. Journal of Financial Economics, 91, 158-178. 
Bhagat, S., Brickley, J. A., \& Lowenstein, U. (1987). The pricing effects of interfirm cash tender offers. Journal of Finance, 42, 965-986.

Bharath, S. T., \& Dittmar, A. (2010). Why do firms use private equity to opt out of public markets? Review of Financial Studies, 23, 1771-1818.

Bjerksund, P., \& Stensland, G. (1993). American exchange options and a put-call transformation: A note. Journal of Business Finance and Accounting, 20, 761-764.

Black, F., \& Scholes, M. (1973). The pricing of options and corporate liabilities. Journal of Political Economy, $81,637-654$

Boehmer, E., Musumeci, J., \& Poulsen, A. B. (1991). Event-study methodology under conditions of eventinduced variance. Journal of Financial Economics, 30, 253-272.

Boot, A., Gopalan, R., \& Thakor, A. (2006). The entrepreneur's choice between private and public ownership. Journal of Finance, 61, 803-836.

Borochin, P. A. (2014). When does a merger create value? Using option prices to elicit market beliefs. Financial Management, 43(2), 445-466.

Calomiris, C. W., \& Hitscherich, D. M. (2007). Banker fees and acquisition premia for targets in cash tender offers: Challenges to the popular wisdom on banker conflicts. Journal of Empirical Legal Studies, 4, 909-938.

Chacko, G., Jurek, J., \& Stafford, E. (2008). The price of immediacy. Journal of Finance, 63, 1253-1290.

Cherkes, M., Sagi, J., \& Stanton, R. (2009). A liquidity-based theory of closed-end funds. Review of Financial Studies, 22, 257-297.

Chernozhukov, V., Fernández-Val, I., \& Kowalski, A. E. (2015). Quantile regression with censoring and endogeneity. Journal of Econometrics, 186, 201-221.

Cheung, W. M., Chung, R., \& Fung, S. (2015). The effects of stock liquidity on firm value and corporate governance: Endogeneity and the REIT experiment. Journal of Corporate Finance, 35, 211-231.

Cochrane, J. H. (2004). Asset pricing: Liquidity, trading, and asset prices. NBER Reporter Online, Winter 2004/05, 1-12.

Cooney, J., Moeller, T., \& Stegemoller, M. (2009). The underpricing of private targets. Journal of Financial Economics, 93, 55-66.

Cooper, S. K., Groth, J. C., \& Avera, W. E. (1985). Liquidity, exchange listing and common stock performance. Journal of Economics and Business, 37, 19-33.

Cornelli, F., \& Li, D. (2002). Risk arbitrage in takeovers. Review of Financial Studies, 15, 837-868.

Cowan, A. R. (1992). Nonparametric event study tests. Review of Quantitative Finance and Accounting, 2, 343-358.

Croci, E., \& Petmezas, D. (2010). Minority shareholders' wealth effects and stock market development: Evidence from increase-in-ownership M\&As. Journal of Banking \& Finance, 34, 681-694.

Das, S., \& Hanouna, P. (2010). Run lengths and illiquidity. Annals of Operations Research, 176, 127-152.

Datar, V. T., Naik, N. Y., \& Radcliffe, R. (1998). Liquidity and stock returns: An alternative test. Journal of Financial Markets, 1, 205-219.

DerSimonian, R., \& Laird, N. (1986). Meta-analysis in clinical trials. Controlled Clinical Trials, 7, 177-188.

Eckbo, B. E., \& Thorburn, K. S. (2000). Gains to bidder firms revisited: Domestic and foreign acquisitions in Canada. Journal of Financial and Quantitative Analysis, 35, 1-25.

Faccio, M., McConnell, J., \& Stolin, D. (2006). Returns to acquirers of listed and unlisted targets. Journal of Financial and Quantitative Analysis, 41, 197-220.

Fang, V. W., Noe, T. H., \& Tice, S. (2009). Stock market liquidity and firm value. Journal of Financial Economics, 94, 150-169.

Fishman, M. J. (1989). Preemptive bidding and the role of the medium of exchange in acquisitions. The Journal of Finance, 44, 41-57.

Fong, K., Holden, C., \& Trzcinka, C. (2011) What are the best liquidity proxies for global research? SSRN working paper, http://ssrn.com/abstract=1558447.

Fuller, K., Netter, J., \& Stegemoller, M. (2002). What do returns to acquiring firms tell us? Evidence from firms that make many acquisitions. Journal of Finance, 57, 1763-1793.

Gilli, M., \& Schumann, E. (2012). Heuristic optimisation in financial modelling. Annals of Operations Research, 193, 129-158.

Gomes, A. (2001). Takeovers, freezeouts, and risk arbitrage. University of Pennsylvania, Center for Analytic Research in Economics and the Social Sciences, unpublished paper, accessed from http://papers.ssrn. com/sol3/papers.cfm?abstract_id=277109.

Gorton, G. B., \& Pennacchi, G. G. (1993). Security baskets and index-linked securities. The Journal of Business, $66,1-27$.

Goyenko, R. Y., Holden, C. W., \& Trzcinka, C. A. (2009). Do liquidity measures measure liquidity? Journal of Financial Economics, 92, 153-181. 
Hamermesh, L. A., \& Wachter, M. L. (2009). Rationalizing appraisal standards in compulsory buyouts. Boston College Law Review, 50(4), 1021.

Hansen, R. (1987). A theory for the choice of exchange medium in mergers and acquisitions. Journal of Business, 60, 75-95.

Hansen, L., Heaton, J., \& Yaron, A. (1996). Finite-sample properties of some alternative GMM estimators. Journal of Business and Economic Statistics, 14(3), 262-280.

Heston, S. L., \& Nandi, S. (2000). A closed-form GARCH options valuation models. Review of Financial Studies, 6, 327-343.

Holmstrom, B., \& Tirole, J. (1993). Market liquidity and performance monitoring. Journal of Political Economy, 101, 678-709.

Jaffe, J., Jindra, J., Pedersen, D., \& Voetmann, T. (2015). Returns to acquirers of public and subsidiary targets. Journal of Corporate Finance, 31, 246-270.

Jindra, J., \& Walking, R. A. (2004). Speculation spreads and the market pricing of proposed acquisitions. Journal of Corporate Finance, 10(2004), 495-526.

Kyle, A. (1985). Continuous auctions and insider trading. Econometrica, 53, 1315-1335.

Lee, K. Y., \& Chung, K. H. (2013). Liquidity and returns to target shareholders in the market for corporate control: Evidence from the US markets. Journal of Business Finance and Accounting, 40, 142-171.

Lehn, K., \& Poulsen, A. (1989). Free cash flow and stockholder gains in going private transactions. Journal of Finance, 44, 771-787.

Lesmond, D., Ogden, J., \& Trzcinka, C. (1999). A new estimate of transaction costs. Review of Financial Studies, 12, 1113-1141.

Lin, J. C., Singh, A. K., \& Yu, W. (2009). Stock splits, trading continuity, and the cost of equity capital. Journal of Financial Economics, 93, 474-489.

Loderer, C., \& Jacobs, A. (1995). The Nestlé crash. Journal of Financial Economics, 37, 315-339.

Longstaff, F. A., \& Schwartz, E. S. (2001). Valuing American options by simulation: A simple least squares approach. The Review of Financial Studies, 14, 113-147.

Madan, D., Roynette, B., \& Yor, M. (2008). Option prices as probabilities. Finance Research Letters, 5, 79-87. https://doi.org/10.1016/j.frl.2008.02.002.

Malatesta, P. H. (1983). The wealth effect of merger activity and the objective functions of merging firms. Journal of Financial Economics, 11, 155-181.

Margrabe, W. (1978). The value of an option to exchange one asset for another. Journal of Finance, 33, $177-186$.

Marshall, B. R., Nguyen, N. H., \& Visaltanachoti, N. (2013). Liquidity measurement in frontier markets. Journal of International Financial Markets, Institutions and Money, 27, 1-12. https://doi.org/10.1016/j. intfin.2013.07.011.

Massa, M., \& Xu, M. (2013). The value of (stock) liquidity in the M\&A market. Journal of Financial and Quantitative Analysis, 48, 1463-1497.

Maug, E. (2006). Efficiency and fairness in minority freezeouts: Takeovers, overbidding, and the freeze-in problem. International Review of Law and Economics, 26, 355-379.

Maynes, E., \& Rumsey, J. (1993). Conducting event studies with thinly traded stocks. Journal of Banking \& Finance, 17, 145-157.

Mehran, H., \& Peristiani, S. (2010). Financial visibility and the decision to go private. Review of Financial Studies, 23, 519-547.

Officer, M. (2007). The price of corporate liquidity: Acquisition discounts for unlisted targets. Journal of Financial Economics, 83, 571-598.

Pastor, L., \& Stambaugh, R. (2003). Liquidity risk and expected stock returns. Journal of Political Economy, $111,642-685$.

Patell, J. M. (1976). Corporate forecasts of earnings per share and stock price behavior: Empirical test. Journal of Accounting Research, 14, 246-276.

Perrakis, S., \& Zhong, R. (2017). Liquidity risk and volatility risk in credit spread models: A unified approach. European Financial Management, 23, 873-901.

Roll, R. (1984). A simple implicit measure of the effective bid-ask spread in an efficient market. The Journal of Finance, 39, 1127-1139.

Sarr, A., \& Lybek, T. (2002). Measuring liquidity in financial markets. IMF Working Paper, WP/02/232.

Shleifer, A. (1986). Do demand curves for stocks slope downward? Journal of Finance, 41, 579-590.

Shleifer, A., \& Vishny, R. W. (1986). Large shareholdings and corporate control. Journal of Political Economy, 94, 461-488.

Stock, J. H., Yogo, M., \& Wright, J. (2002). A survey of weak instruments and weak identification in generalized method of moments. Journal of Business and Economic Statistics, 20, 518-529. 
Subramanian, G. (2007). Post-Siliconix freeze-outs: Theory and evidence. The Journal of Legal Studies, 36, 1-26.

Sudarsanam, S., \& Sorwar, G. (2010). Determinants of takeover premium in cash-financed takeover offers: An option pricing approach. Journal of Business, Finance and Accounting, 37, 687-714.

Wurgler, J., \& Zhuravskaya, E. (2002). Does arbitrage flatten demand curves for stocks? The Journal of Business, 75, 583-608. 